\title{
Tratos, batallas y malones. El accionar indígena en la frontera sur durante el sitio a la ciudad de
} Buenos Aires

Treaties, battles and "malones". The indigenous action in the south border during the siege to the city of Buenos Aires

\section{María Fernanda Barcos}

\section{(2) OpenEdition}

Journals

\section{Electronic version}

URL: http://journals.openedition.org/corpusarchivos/1871

DOI: 10.4000/corpusarchivos. 1871

ISSN: 1853-8037

\section{Publisher}

Diego Escolar

\section{Electronic reference}

María Fernanda Barcos, «Tratos, batallas y malones. El accionar indígena en la frontera sur durante el sitio a la ciudad de Buenos Aires », Corpus [En línea], Vol. 7, No 1 | 2017, Publicado el 07 julio 2017 , consultado el 10 diciembre 2020. URL : http://journals.openedition.org/corpusarchivos/1871 ; DOI https://doi.org/10.4000/corpusarchivos. 1871

This text was automatically generated on 10 December 2020.

Licencia Creative Commons: Atribución-NoComercial 2.5 Argentina (CC BY-NC 2.5 AR) 


\title{
Tratos, batallas y malones. El accionar indígena en la frontera sur durante el sitio a la ciudad de Buenos Aires
}

Treaties, battles and "malones". The indigenous action in the south border during the siege to the city of Buenos Aires

\author{
María Fernanda Barcos
}

\section{EDITOR'S NOTE}

Fecha de recepción del original:

Fecha de aceptación para publicación:

Una versión previa de este trabajo fue presentada en las XXV Jornadas de Historia Económica.

Agradezco los comentarios a la ponencia que se realizaron alli, especialmente a Juan Luis Martiren. También la lectura que realizó Sol Lanteri a una versión posterior. Los errores que puedan encontrarse son responsabilidad de la autora.

\section{Introducción}

1 Luego de la derrota que sufrió en Caseros el gobierno de Juan Manuel de Rosas a manos del Ejército Grande, Buenos Aires atravesó un período de absoluta inestabilidad política que duraría varios años. Los enfrentamientos se produjeron en dos planos relacionados pero diferentes, vinculados por un lado con la política estrictamente bonaerense y por el otro con el enfrentamiento entre el Estado de Buenos Aires (1854) y la Confederación Argentina. Como telón de fondo se sumó el conflicto indígena. La asociación que se había 
creado en torno al Ejército Grande ${ }^{1}$ solo tenía en común el deseo de terminar con Rosas; una vez cumplido el cometido, la presencia militar de Urquiza se transformó para la elite que aspiraba a dirigir la provincia de Buenos Aires en un problema. Su historia dentro de la facción federal, la serie de medidas que implementó en la ciudad de Buenos Aires ${ }^{2}$ y el rápido intento de organizar constitucionalmente el país bajo sus criterios provocaron resquemor entre los políticos de la ciudad de Buenos Aires y desataron en muy poco tiempo una nuevo enfrentamiento, esta vez dirigido contra Urquiza, el "nuevo tirano".

2 El suceso aludido pasó a la historia con el nombre de "Revolución del 11 de Septiembre". Las causas además estuvieron relacionadas con la elección de Vicente López y Planes como gobernador provisorio, puesto que la decisión obviaba las preferencias que tenían los legisladores de Buenos Aires por Valentín Alsina y su presencia en la reunión de gobernadores que se realizaba en el pueblo de San Nicolás con la idea de convocar un Congreso Constituyente. La situación se tensó con la renuncia de Planes y el interinato del general Manuel Pintos confirmado por la Sala de Representantes, ya que Urquiza reaccionó reponiendo a su gobernador, clausurando la Legislatura y enviando al exilio a las figuras opositoras más relevantes. La resistencia porteña a la intervención se mantuvo, no obstante, con el apoyo de un grupo heterogéneo de oficiales y de los referentes políticos de la ciudad. Así, y siendo el enfrentamiento entre Buenos Aires y la Confederación un hecho, el 11 de septiembre de 1852, aprovechando la ausencia física de Urquiza, quien viajaba a la provincia de Santa $\mathrm{Fe}$ para inaugurar las sesiones del Congreso, se produjo la rebelión que inició la separación de la provincia de Buenos Aires del resto de la Confederación, eligiendo a Valentín Alsina como gobernador (Cárcano 1946; Scobie 1964).

3 La revuelta permitió el alejamiento de Urquiza, pero la heterogeneidad de aspiraciones de quienes participaron provocó que la coalición se quebrara rápidamente. Influyeron sobre todo las diferencias que existían entre los militares identificados con el federalismo; estos se debatían entre la lealtad federal hacia Urquiza -con el recelo de ocupar un papel secundario en su administración-y la adhesión a un movimiento propio de Buenos Aires, pero liderado por antiguos enemigos a los que tenían que subordinarse (Scobie 1964). La disyuntiva se agudizó cuando el nuevo gobierno planeó expandir a las provincias su movimiento. Muchos de los oficiales comenzaron a disentir con esta política, aun habiendo sido recompensados, y debido a ello el 22 de septiembre fueron desterrados. Entre los militares expulsados se encontraba el general Hilario Lagos (Barcos 2012).

El general Hilario Lagos se había incorporado a las filas del rosismo en 1840 para contrarrestar la invasión de Lavalle a Buenos Aires, luego de una extensa carrera en la frontera. En 1844 se incorporó a las tropas de Urquiza en Entre Ríos, pero cuando este se pronunció contra Rosas, presentó su dimisión al cargo. A partir de este momento integró la defensa de la provincia junto a las tropas federales de vanguardia hasta su participación en la batalla de Caseros en febrero de 1852. Posteriormente, el gobierno de Urquiza en Buenos Aires lo nombró comandante militar del Departamento del Sur, cargo que desempeñó hasta su renuncia en mayo de 1852. Ya como gobernador, Alsina lo reasignó en el mismo cargo, pero renunció casi inmediatamente. Vuelto del destierro al que fue sometido por negarse a cumplir órdenes, y pese a sus negativas, se lo designó como comandante del Departamento del Centro con sede en el pueblo de la Guardia de Luján. Desde este último cargo se pronunció contra el gobernador propietario el $1^{\circ}$ de diciembre de 1852. 
5 La rebelión rural que se desató en contra del gobierno "separatista" de Valentín Alsina fue liderada inicialmente por Lagos en complicidad con el general José María Flores y fue sostenida por la mayoría de la oficialidad federal. Esta movilizó a las nuevas Guardias Nacionales de la mayoría de los pueblos de campaña y de esa manera pudo cercar la ciudad de Buenos Aires. El general Flores abandonó rápidamente el movimiento y se mantuvo en el ostracismo hasta los días finales del sitio, cuando apoyó abiertamente a la ciudad; debido a esto el levantamiento quedó bajo las órdenes de Lagos hasta el mes de marzo. A partir de ese momento, los jefes cedieron el mando al líder de la Confederación Argentina, Gral. Justo J. de Urquiza.

Los motivos de la rebelión fueron expuestos por Lagos en una Proclama; ${ }^{3}$ de acuerdo a ella, la provincia se levantaba en masa contra la ofensiva que el Gobierno de Buenos Aires realizaba sobre las provincias vecinas. Cuestión que conducía inexorablemente a una guerra que nadie había autorizado ni deseaba. Entre los argumentos expuestos se encontraba también el rechazo de la oficialidad al nombramiento del general José María Paz como jefe del Ejército y, en documentos posteriores, el pedido de integración de la provincia de Buenos Aires a la Confederación Argentina concurriendo con sus representantes al Congreso Constituyente que se celebraba en Santa Fe.

7 Valentín Alsina renunció al cargo seis días después del levantamiento, sin embargo el conflicto, lejos de detenerse, se agravó. La ciudad fue sitiada por las tropas de la campaña y esta debió armarse para enfrentar un conflicto que duró casi ocho meses. En otros trabajos hemos estudiado esta rebelión, y seguimos haciéndolo desde múltiples aspectos que abarcan gran parte de las problemáticas que se pusieron de manifiesto luego de la caída de Rosas (Barcos 2012). En este artículo queremos centrarnos en un tema específico: las estrategias indígenas frente al conflicto citado, puesto que aún falta analizar este tema desde la óptica de los pueblos de la campaña desde donde se puede observar las dinámicas variables que se generaron en la frontera. Allí los conflictos políticos se insertaron en lógicas diferenciadas, donde las estructuras de poder de la oficialidad civil y militar se relacionaron con la dinámica de cada pueblo y de sus particulares relaciones con el mundo indígena.

Durante los años posteriores a la batalla de Caseros, los pueblos de la campaña estuvieron atravesados por varios conflictos que se relacionaron con el cambio o permanencia de funcionarios locales, la mayor o menor presencia indígena en la zona, los vaivenes en las relaciones laborales producto de las levas y otros. Además del desorden y malestar de la población rural, se sumó el desarreglo logístico de la frontera, cuestión que generó un contexto particular que las diferentes parcialidades aprovecharon. Como bien explicó Bechis (2017, p. 14), los conflictos por el poder durante la segunda mitad del siglo XIX exigieron lealtad de los indígenas de diferentes grupos de indios amigos $\mathrm{y}$, a veces, de todos, de acuerdo a la cantidad de lanceros con que contaba cada parcialidad en ciertos momentos. Así los indígenas participaron activamente de los conflictos políticos durante el sitio, pero no solo como potenciales lanceros sino también con alianzas interétnicas en contra de los criollos y negociando con los diferentes bandos en disputas. También maloneando para adquirir bienes, cautivos y ganado. ${ }^{4}$

De acuerdo a las investigaciones disponibles, sabemos que en los primeros meses posteriores a la caída de Rosas se intentó sostener el negocio pacífico, ya que se mantuvieron los mismos interlocutores de los caciques y el sistema de racionamiento. En el sur, el general Pedro Rosas y Belgrano siguió a cargo del juzgado y comandancia del pueblo de Azul y Manuel Leyba continuó como comandante interino de Bahía Blanca. ${ }^{5}$ Por 
orden de Urquiza se nombró comandante general del Departamento del Sur al coronel Hilario Lagos, de amplia trayectoria en las filas rosistas y en la frontera, donde se había enfrentado a los indios ranqueles y relacionado con los indios amigos del fuerte Federación (Junín). Además, no se alteró el circuito comercial ni resurgió la actividad malonera (Ratto 2015, p. 68). Sin embargo, la situación cambió con los efectos de la separación de Buenos Aires de la Confederación en septiembre de 1852 y el posterior sitio a la ciudad en diciembre del mismo año, que estamos analizando. Solo a modo de ejemplo, el 13 de octubre de 1852 Francisco Olmos como comandante general "desde la ciudad hasta el Vecino" le escribía al entonces ministro de Guerra y Marina, D. José María Pirán, sobre los problemas que existían en el sur para racionar a los indios amigos. Pedro Rosas le había escrito porque:

hasta hoy dia de la fha, no han remitido a este punto los juezes de Paz del Departamento del mando de VS las yeguas pa el consumo de los Indios amigos como les está mandado por la superioridad y como este atrajo es perjudicial á dichos Indios porque carezen de alimento ${ }^{6}$

10 A lo que Olmos respondía: "esta comandancia general ha ignorado hasta la fha el modo como sean de sacar las yeguas para sur remitidas a los indios amigos para ser racionados". ${ }^{7}$ Sin embargo no era del todo así, porque desde abril de 1852 los jefes tenían información sobre cómo se racionaba durante el período rosista. ${ }^{8}$ Más aún, el mismo día Pedro Rosas le escribía a Alsina dando cuenta del número de indios sostenidos en la provincia. ${ }^{9}$ Como puede deducirse, los vaivenes políticos eran muy complejos, del mismo modo que las relaciones de los principales jefes de la frontera sur entre sí y con los jueces de paz. Todo esto se daba en un marco de relaciones interpersonales en las que influían historias de vida, relaciones familiares, jerarquías y posicionamientos políticos. Así, un mismo jefe ante la misma orden superior actuaba de diversa manera de acuerdo a quiénes eran sus superiores políticos y quiénes sus interlocutores. Todo esto obviamente influía en las relaciones con los indios amigos. Estos, además, posiblemente se interpelaron respecto de su estado de "sumisión" en un contexto de conflicto entre los mismos blancos (Bechis 2008, p. 10). En relación con esto, aquí se matizan las afirmaciones que postulan que los indios amigos permanecieron en orden luego de la caída de Rosas y recién se enfrentarían con el Gobierno porteño hacia 1855, puesto que se observa su participación en los saqueos posteriores a la batalla de San Gregorio (Chascomús) y en el malón de febrero de 1853, que generó un alto costo para la economía del sur bonaerense.

\section{Para evitar la guerra, la guerra}

11 Antes de concentrarnos en las cuestiones señaladas, es importante explicitar algunos puntos para orientar al lector. En términos generales, el estado de la campaña en 1852 era muy grave pues venía duramente golpeada por la guerra, el robo y matanza de animales, a lo que se sumó la desmovilización de las milicias y, posteriormente, las levas producto de la intención de los septembristas de extender la autodenominada "revolución" al resto de las provincias. No azarosamente la Proclama de Lagos se centraba en recalcar la necesidad de terminar con la guerra. En función de la movilización de fuerzas como del conjunto de militares de las zonas involucradas, durante los meses de diciembre y enero, el movimiento liderado por Lagos tuvo una importante adhesión en el norte y en el centro de la provincia, mientras que en el sur esta fue menor. Sobre esto último conviene, no obstante, matizar un poco. Los pueblos de la frontera sur no reaccionaron todos de la misma manera. En Dolores, por ejemplo, la guerra de influencias se desató ásperamente 
porque la autoridad del sitiador Olmos era casi paralela a la de Pedro Rosas y Belgrano, que apoyaba a Buenos Aires. ${ }^{10}$ Ambos habían sido comandantes de frontera en la región y tenían relaciones de poder muy fuertes en la zona. Producto de esto, a fines de diciembre, el vecindario se encontraba enfrentado entre sí y alzado en armas. En cambio, Azul y Tapalqué aparecían como los bastiones de Pedro Rosas. Allí, como ya se ha estudiado, se implementó una política particular de entrega de tierras en mediana escala a cambio de contraprestaciones de bienes y servicios (Lanteri 2011). Pero aun así, esto no se tradujo en un alineamiento lineal y automático; para dicho general fue difícil reunir tropas, siendo más proclives a alinearse con él los indios amigos que los milicianos (mayoritariamente donatarios del periodo rosista). Algunos de estos últimos protagonizaron deserciones e incluso encontramos noticias aisladas de milicianos que se pasaron a las filas de los sitiadores (Barcos 2017). Toda esta complejidad se debe a que los alineamientos que generó el movimiento decembrista en cada pueblo se debieron a varios factores imposibles de simplificar y entre los cuales fueron muy importantes: las tradiciones culturales, la importancia y el tipo de presencia militar en la zona, las adscripciones étnicas, las diferentes experiencias de politización previas y las alineaciones de cada pueblo dentro del federalismo rosista junto con las relaciones con los poderes intermedios de la frontera.

Durante los meses de diciembre y enero, tanto la ciudad como la campaña se organizaron para el enfrentamiento desatado desde el pueblo de la Guardia de Luján. ${ }^{11}$ Los alineamientos políticos fueron entonces los primeros asuntos que trató la oficialidad militar involucrada, pero luego de expresados los apoyos y las negativas (las más sonadas fueron la de Lorenzo Torres y José M. Flores porque habían apoyado originalmente el movimiento, mientras que Pedro Rosas y Belgrano se negó a apoyarlo desde el principio) comenzó el proceso de reclutamiento en los pueblos. Los guardias nacionales fueron convocados tanto para marchar a Buenos Aires como para quedar como fuerzas de reserva en los vecindarios..$^{12}$ Para lograr adhesión, el movimiento utilizó un bagaje cultural común -el federalismo-, una estructura político administrativa -los juzgados de paz-y un aparato de coerción eficaz -comandancias, guardias nacionales y ejército de línea- que permitieron organizar eficazmente la reunión de hombres para cercar la capital. Por supuesto que entre los jueces los había reacios al movimiento y adeptos; respecto de los primeros se operó una extrema vigilancia que incluyó deposiciones y algunos encarcelamientos.

La ciudad también se organizó, se declaró el pueblo en asamblea debiendo toda la Guardia Nacional concurrir a las armas. ${ }^{13}$ En segunda instancia, se aceptó la renuncia de Valentín Alsina y se designó interinamente a Manuel Pinto; este debía lograr que los militares sublevados reconocieran su autoridad y luego licenciarlos. La Sala de Representantes se prestó a sesionar diariamente y fue autorizada, sin previo juicio, a arrestar y remover fuera de la provincia a todos los individuos sospechosos. Del mismo modo, dispondría del tesoro público para gastos de guerra. En términos de logística, se organizó la resistencia de la ciudad con alrededor de 3.000 hombres armados dirigidos por una Junta de Guerra presidida por el Gral. José M. Paz y Gervasio Espinoza. ${ }^{14}$

\section{El conflicto en la frontera sur}

14 En la campaña, los chasques cruzaban las regiones constantemente y llevaban de una a otra toldería información sobre lo que sucedía en Buenos Aires y entre Buenos Aires y la 
Confederación. Por ejemplo, el posicionamiento de Pedro Rosas a favor de la ciudad y en contra de Lagos fue conocido por los indios ranqueles (que tenían tratativas por esos días con Urquiza) ya en los primeros días de enero. Siguiendo a Bechis (2002), en 1850 tres agrupaciones indígenas dominaban las pampas y el norte de la Patagonia. En el norte habitaban los ranqueles, quienes tenían la capacidad de montar un ejército de entre $700 \mathrm{y}$ 1.000 guerreros. En el centro de la actual provincia de Buenos Aires se ubicaban los llamados chilenos o salineros. Su jefe era Calfucurá, quien provenía de la Cordillera y había construido su liderazgo a partir del enfrentamiento exitoso (1834) con los boroganos, una agrupación netamente araucana. Calfucurá podía poner, como mínimo, 2.000 guerreros en pie de guerra. Finalmente, el sur más lejano estaba dominado al norte por los tehuelches en contacto con Carmen de Patagones y Bahía Blanca y, al oeste, en el País de las Manzanas, por cordilleranos, indios de la zona de Valdivia y tehuelches. Las agrupaciones citadas eran indios soberanos que a veces se aliaban y en otros momentos actuaban como enemigos frente a los criollos. En cambio, dentro de la frontera militar se encontraban los indios amigos o reducidos. Aquellos que a cambio de recibir raciones acordaban subordinarse a las autoridades militares. Realizaban también diferentes tareas, como emplearse en estancias o servir de chasques y baqueanos (Ratto 2003). Desde los años 20, los pampas Catriel y Cachul, que luego se ubicaron en la zona de Azul y Tapalqué. Por otra parte, el jefe Coliqueo, de origen chileno-borogano, quien llegó a las pampas en 1820 pero se estableció en Bragado durante la segunda mitad del siglo.

Para diciembre de 1852, la organización de la campaña había cambiado respecto del período rosista, por lo menos en términos nominales. El decreto del 17 de marzo de 1852 había disuelto las milicias y ordenaba establecer la defensa en regimientos de guardias nacionales; sabemos sin embargo que la ordenación definitiva de estos se realizó años después y no fue un proceso simple. Para diciembre de 1852, sin embargo, estas ya suplantaban a las milicias en varios puntos. En la frontera sur, desde mediados de 1852, se había organizado el Regimiento № 11 (Azul, Las Flores y Tapalqué) al mando del capitán Pedro Rosas y Belgrano, el № 12 (Dolores, Pila, Tordillo y Vecino) bajo las órdenes del coronel Sixto Casanoba, el № 13 (Mar Chiquita, Tuyú y Ajó) sin jefe y el 14 (Lobería y Chapaleufú) al mando del sargento Mariano Calderón. No obstante su formación, la organización era complicada y durante la mayor parte del año 1852 los jefes se quejaban de la falta de hombres y recursos (Caletti 2014, p. 74).

Cuando estalló el conflicto entre el separatismo porteño y las tropas federales de la campaña, los alineamientos de los jefes de las GN comenzaron inmediatamente. Los Departamentos del Norte y del Centro cerraron filas rápidamente con Hilario Lagos y José María Flores, mientras que el sur fue una incógnita durante varios días. El comandante general del Departamento del Sur, Cnel. Francisco Olmos, se sumó al movimiento, del mismo modo que Eugenio del Busto, jefe del Regimiento de Blandengues y luego Cte. del $2^{\circ}$ Dto. del Sur. ${ }^{15}$ También Rafael Burgos [Burgeois], Cte. del Regto. $\mathrm{N}^{\circ} 15$ de GN (fuerte Argentino-Bahía Blanca). Mientras tanto, Pedro Rosas no se pronunciaba y las versiones que llegaban al cuartel de San José de Flores eran confusas, al punto de que Juan F. Olmos decidió reunirse con Lagos para hablar personalmente sobre el tema y sobre la posibilidad de torcer la influencia de Pedro Rosas en el sur. Otra de las figuras claves con la que contaba Lagos para persuadir a Pedro Rosas era Antonino Reyes, quien retornó a Buenos Aires desde Montevideo para apoyar el sitio. ${ }^{16}$ El 23 de diciembre informaba haber encontrado en el Salado a varios jefes con tropa: 
como con 70 de distintos cuerpos que estaban en el Azul (...) Y estos me dicen que se han venido de aquel punto buscando la incorporación a sus "gefes" que saben han dado el grito de "Federación" y por saber que Don Pedro Rosas se ha pronunciado a favor de nuestros enemigos (...) Que también se han desbandado otros pequeños grupos que habían reunido en Tapalque, Tandil y Dolores ${ }^{17}$

La gente toda del Azul se viene en partidas y después de los setenta de los que le hablé a V. S. van otra porción de grupos que siembran por donde pasan el descontento general y desparraman vozes que influirán indudablemente para el desprestigio de Don Pedro. Tengo noticia que la reunión de la Loberia asi que se supo el objeto se deshizo y habiendo querido contener el Juez de Paz Otamendi casi lo mataron y después deshicieron una partida del Juzgado que también quizo atajar un pequeño grupo matando uno de los soldados de dicha Partida y me han asegurado también que algunos grupos de esta reunión habían seguido para adentro a presentarse a V.S. ${ }^{18}$

Pedro Rosas finalmente apoyó al bando porteño y se dirigió al sur para recolectar adeptos; no obstante Olmos, que también se encontraba allí, intentaba lograr más y mejores influencias sobre la oficialidad y los pobladores. De acuerdo a la información que recolectaba Reyes, la posibilidad de captar adhesiones para el bando porteño tenía mayores posibilidades de éxito entre los criollos que entre los indígenas. Los sitiadores, enterados de la situación, reforzaron su presencia en la región; para dicha tarea utilizaron a Francisco Olmos quien conocía la zona, a los funcionarios y a los milicianos, puesto que muchos de ellos habían participado en campañas anteriores con él. Más allá de las estrategias, el reclutamiento no fue fácil para ninguno de los bandos: "la gauchada no obedece ni a uno ni a otro partido por la desconfianza en que viven e ignorancia que tienen de nuestras actualidades". ${ }^{19}$ Esto era así porque usualmente se manejaba información estratégica, pero también abundaban los "rumores". Los protagonistas de los acontecimientos tenían sus propias herramientas para manejar la información y la ponderaban de diferente manera. Situación clásica de las sociedades campesinas del período en el cual las vías de comunicación eran fundamentalmente orales. Hasta donde pudimos observar por la correspondencia, existía un clima de agitación permanente y el reclutamiento era dificultoso. En cuanto a los indígenas, Rosas había logrado juntar 700 en Azul aunque "al parecer los indios no vienen a gusto porque me dicen que se andan empacando". ${ }^{20}$ A gusto o no, de allí se dirigieron al pueblo Dolores para incorporarse al resto de las fuerzas. Otra noticia llegaba de Las Flores:

Pedro Rosas ha salido del Azul con dirección al Tuyú con Indios y alguna otra gente armada, llevando tres carretas de convoy se le volvieron todos los indios, y la otra gente se le desparramó a diferentes rumbos; que el precisamte se debió haber embarcado en el Tuyú que dho convoy quedó tirado en el campo. ${ }^{21}$

Del parte de los sitiadores, el jefe del Ejército Mayor comunicaba a Lagos que ellos contaban también con otra fracción de indios amigos para luchar. Por ejemplo, Melinao y Reilef acompañaron a Eugenio del Busto y a Laureano Díaz como cuerpo auxiliar del Regimiento de Blandengues (Ratto 2015, p. 71). Como puede observarse entonces, durante estos dos meses hubo participación de indios amigos en las filas de Lagos y, sobre todo, en la de Rosas y Belgrano.

20 Las parcialidades de fuera intervinieron también en el conflicto generando, armando y desarmando alianzas estratégicas. Los primeros días de enero se había celebrado en Leubucó un parlamento de los caciques ranqueles al que asistieron Baigorria, Calvaiñ y Pichuiñ. En dicha reunión se comprometieron a aliarse a la Confederación Argentina y a 
no invadir las fronteras federales; no obstante, los días posteriores las alianzas se fueron modificando porque, además, los caciques Calvaiñ y Pichuiñ, desde 1852, se venían diferenciando en su política con los criollos. ${ }^{22}$

21 El 6 de enero el cacique Calvaiñ informaba al Gobierno de las provincias de Córdoba y Santa Fe que permitiría que sus indios fueran a invadir Buenos Aires porque "sus indios se hallan escasos y por consiguiente padecen ambre". La incursión se realizaría "desde Rosario para abajo, muy particularmente por Bahía Blanca, Patagonica y otros puntos". ${ }^{23}$ Las autoridades de la Confederación intentaron -circunstancialmente- detener a Calvaiñ y para ello utilizaron de intermediario a Baigorria mediante el envío de correspondencia. La carta enviada constaba de tres partes, se emitía una queja sobre la actitud de Calvaiñ "que persuadido de la imprudencia y mala fé con que se maneja Calvan y los indios de él, que jamás se hallan contentos con lo que se les regala" y se informaba sobre la posible invasión. Aquí se observa claramente el argumento que plantea la interrelación entre ración y malón para obtener ganado, si la primera actividad no funcionaba quedaba abierta la segunda opción amparada por la quita de territorio por parte del blanco (Foerster y Vezub 2011, p. 274).

En la tercera parte se agregaba:

Esta es una equivocación de Galvan, por que U sabe que toda la capaña de Buenos Aires esta por el General Urquiza, y que solamente las calles de Buenos Aires están aún sostenidas y eso porque el General Urquiza no quiere echarles el Pueblo abajo, y por lo tanto esto mismo esperamos le haga U presente a Calvan si le fuera posible; pues si siempre persistiese en invadir, cuando lo intente nos haga un chasque avisándonos; que el Gral Urquiza y todo el Pais le agradecerá sus importantes servicios. A sus suegros y compañero les he regalado todo cuanto me ha sido posible de un modo mejor, basta que sean Indios del amigo Pichun. ${ }^{24}$

En lo inmediato la invasión no se produjo, pero los caciques ranqueles siguieron de cerca la situación de la campaña de Buenos Aires y fueron organizándose al punto que para febrero entrarían también en tratativas con el cacique Calfucurá de Salinas Grandes y elaborarían una nueva estrategia. ${ }^{25}$ 


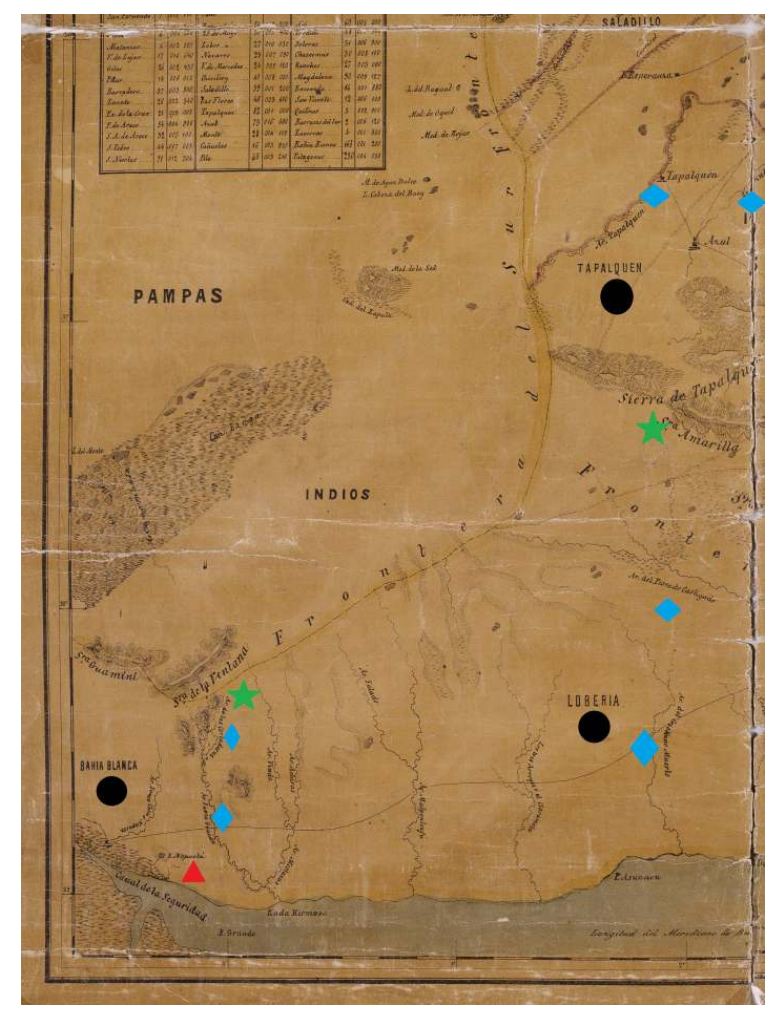

Mapa 1: Principales partidos y parajes de conflicto en la frontera sur

Fuente: Carta de la provincia de Buenos Aires, 1862 "delineada según los datos que existen en el Departamento Topográfico de la Provincia por el Sr. Coronel Arenales antiguo gefe de dicho Departamento; Es aumentada en la parte Topografica itineraria y de la división administrativa por el Ingeniero Nicolás Grondona".

\section{Frente a frente: la batalla de San Gregorio}

El 14 de enero de 1853 las dos fuerzas, la de la ciudad organizada por Pedro Rosas y la de los sitiadores, se avistaron en la laguna de Lastra. Ambas tenían entre sus filas a milicianos e indios amigos. Pedro Rosas logró inicialmente una ventaja sobre la fuerza de observación que tenía Olmos y esto le dio confianza para seguir avanzando. La noticia de la retirada de los sitiadores llegó rápido a la ciudad, que la celebró como una auténtica victoria:

Las importantísimas noticias...anuncian ya de un modo indudable el triunfo completo de nuestras instituciones, y un porvenir feliz para nuestra querida Patria, a quien unos pocos malvados han querido entregar amarrada al General Urquiza (... ) el arrojo de nuestra valiente vanguardia, ya anuncio a nuestro Ejército el completo triunfo, porque introdujo tal desorden en las ordas de $\mathrm{Olmos}^{26}$

Para Olmos, sin embargo, la retirada no significaba un fracaso puesto que la división del Cnel. Bustos llegaba desde el oeste en su ayuda y, además, desde Ranchos marchaba la del Cnel. Cesáreo Domínguez. Y para el 21 de enero también se encontraban reunidos Gregorio Paz y Gerónimo Costa, ambos llegados desde Magdalena. Pedro Rosas ignoraba la reunión de fuerzas en Chascomús y que se habían perdido los buques con provisiones, en ese desconocimiento avanzó sobre el Salado con la idea de recoger los víveres que les habían prometido. 
Con mayor información y fuerzas, los sitiadores decidieron finalmente enfrentarse con Pedro Rosas en el encierro que significaban los ríos Salado y Samborombón. El 22 de enero, en campos de San Gregorio (Chascomús), finalmente se produjo la batalla. Las fuerzas de Rosas y Belgrano eran de 2.000 soldados y 500 indios amigos de Tapalqué, mientras que el Ejército Federal estaba integrado por 3.500 soldados de las tres fuerzas y por indios amigos de Bragado.

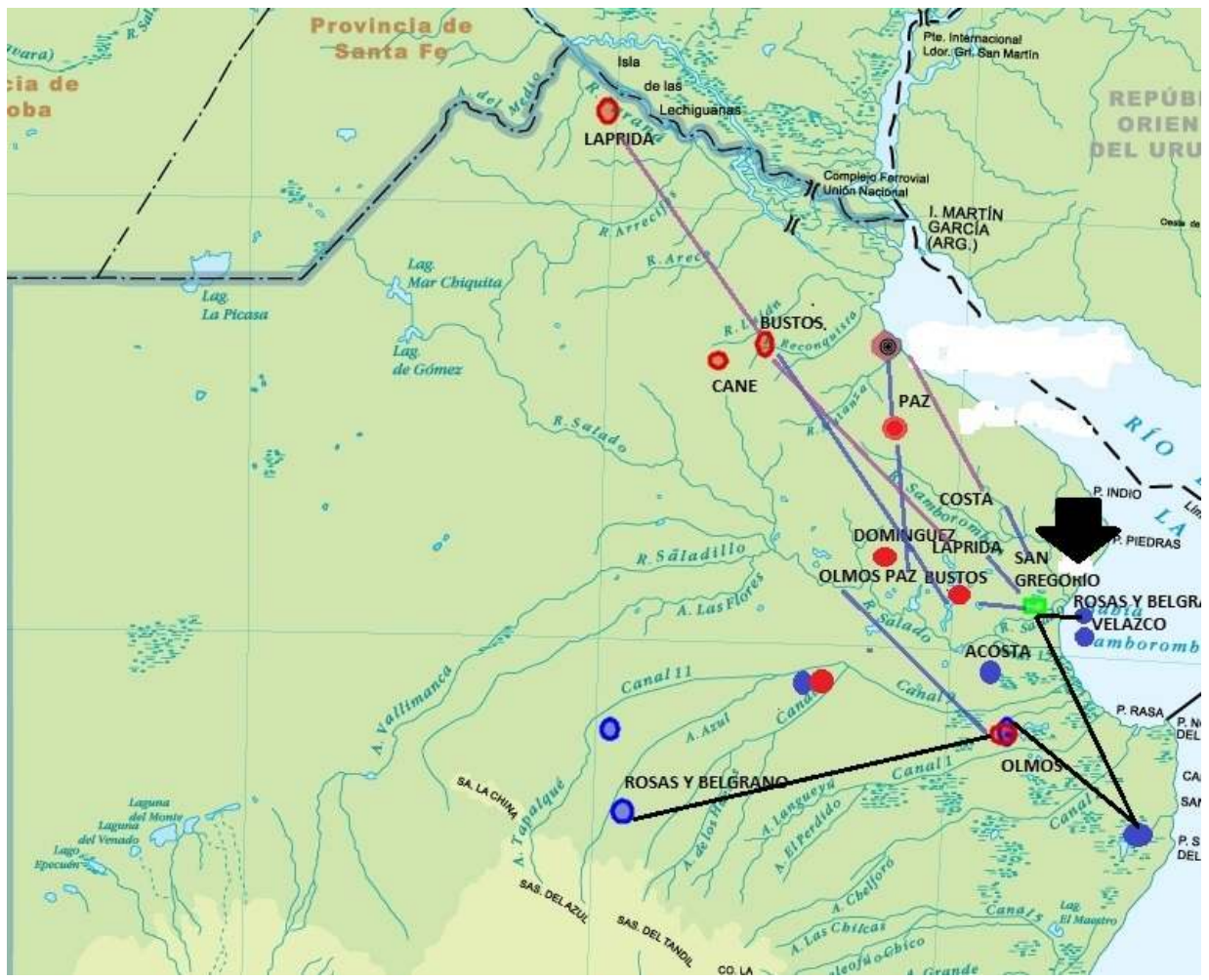

MAPA 2

\section{Movimiento de fuerzas para la batalla en San Gregorio}

Fuente: Elaboración propia

El resultado final fue favorable a los sitiadores, la caballería de Pedro Rosas fue derrotada y comenzó la dispersión hacia el sur. En dicha huida muchos hombres terminaron ahogados en el Salado, mientras que toda la infantería y artillería fue hecha prisionera. También oficiales de alto rango y el mismo Pedro Rosas y Belgrano.

El relato que hace Olmos en su parte de batalla es bien interesante, explica el éxito de la incursión por razones de liderazgo y por el "triunfo de la opinión" que los combatientes tenían de Urquiza, de Lagos y de él mismo. Según sus palabras, los paisanos no querían batirse con él por la labor que había tenido en la campaña sur. ${ }^{27}$ Más allá de su propio ensalzamiento, lo cierto es que muchos integrantes del ejército de Pedro Rosas se pasaron de bando luego de tres horas de inacción y deliberación. En tanto que los indígenas parlamentaron entre ellos y decidieron primero la neutralidad y luego la defección. En la retirada a Tapalqué saquearon campos y propiedades (ver cuadro 1 anexo). 

Constituido ya el Gobierno del Estado de Buenos Aires, su ministro de Gobierno, Ireneo Portela, ordenó al juez de paz de Chascomús que recogiera los restos humanos que habían quedado en el campo de batalla y los sepultara en el cementerio del pueblo de Chascomús. 28

Con la pérdida del control del puerto y el fracaso de la incursión a la campaña, la ciudad atravesaba su peor momento. Se puso en vigor la Ley Marcial y se nombró a Ángel Pacheco enviado extraordinario en misión especial con Brasil para que intentara resolver el conflicto. Además, se organizaron mejor los puntos de defensa de la ciudad y se autorizó a los jefes de las GN a entrar en las casas particulares a buscar desertores. Por último, se incentivó a las tropas con ascensos como en el caso del Batallón de Buenos Aires de la ciudad, denominado ahora Cuerpo de GN.

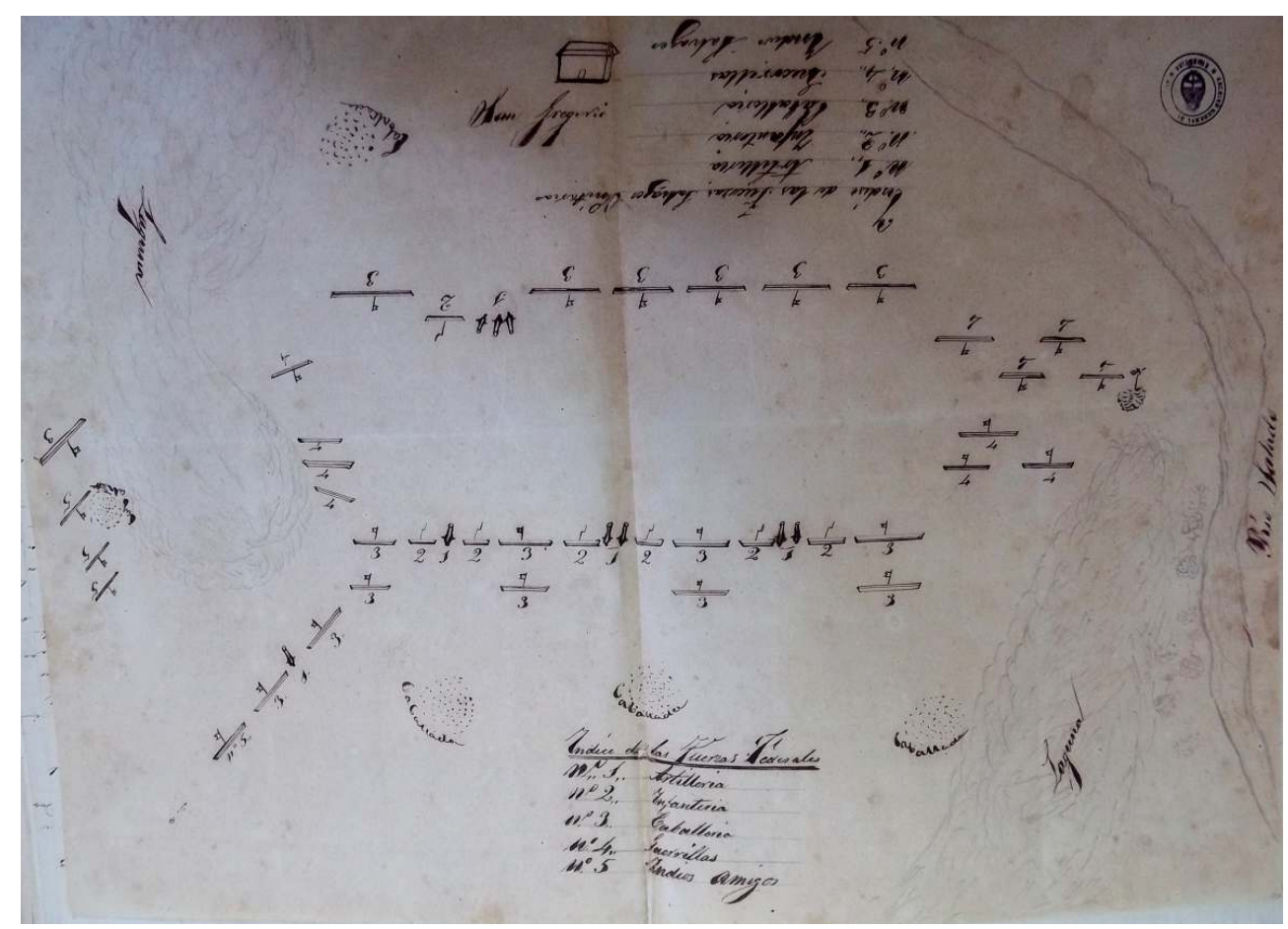

MAPA 3

Croquis de la batalla de San Gregorio

Fuente: AGN, AF, CL, Leg. 263, 5 de enero de 1853.

31 El cuadro 1 resume los daños denunciados por los dueños, encargados o pobladores de los establecimientos de Las Flores que fueron atacados por los indios de Tapalqué luego de la batalla de San Gregorio. La variedad de artículos, sumado al ganado y cuero que fueron denunciados como sustraídos, hacían del malón una verdadera empresa de saqueo en la que debieron participar muchos hombres. Los animales robados fueron mayoritariamente trasladados hasta las tolderías. El 11 de febrero Isidro Jurado le escribía a Eugenio del Busto desde Tapalqué diciendo que le habían sido devueltas 2.500 cabezas robadas por la indiada de Catriel y Yanquenecul. Sin embargo, relataba que los indios aún tenían vacas y terneros; esgrimían que estos animales eran de ellos. Jurado explicaba que para saberlo 
con certeza tenía que ir algún criollo conocedor de las marcas, pero esto era imposible porque no había caballos en el pueblo para llegar hasta a las tolderías e intentar traer la hacienda. ${ }^{29}$

\section{CUADRO 1}

"Investigación de los estragos, robos y asesinatos de los indios ladrones de Tapalqué hubiesen cometido en el Partido de mi cargo [Las Flores]"

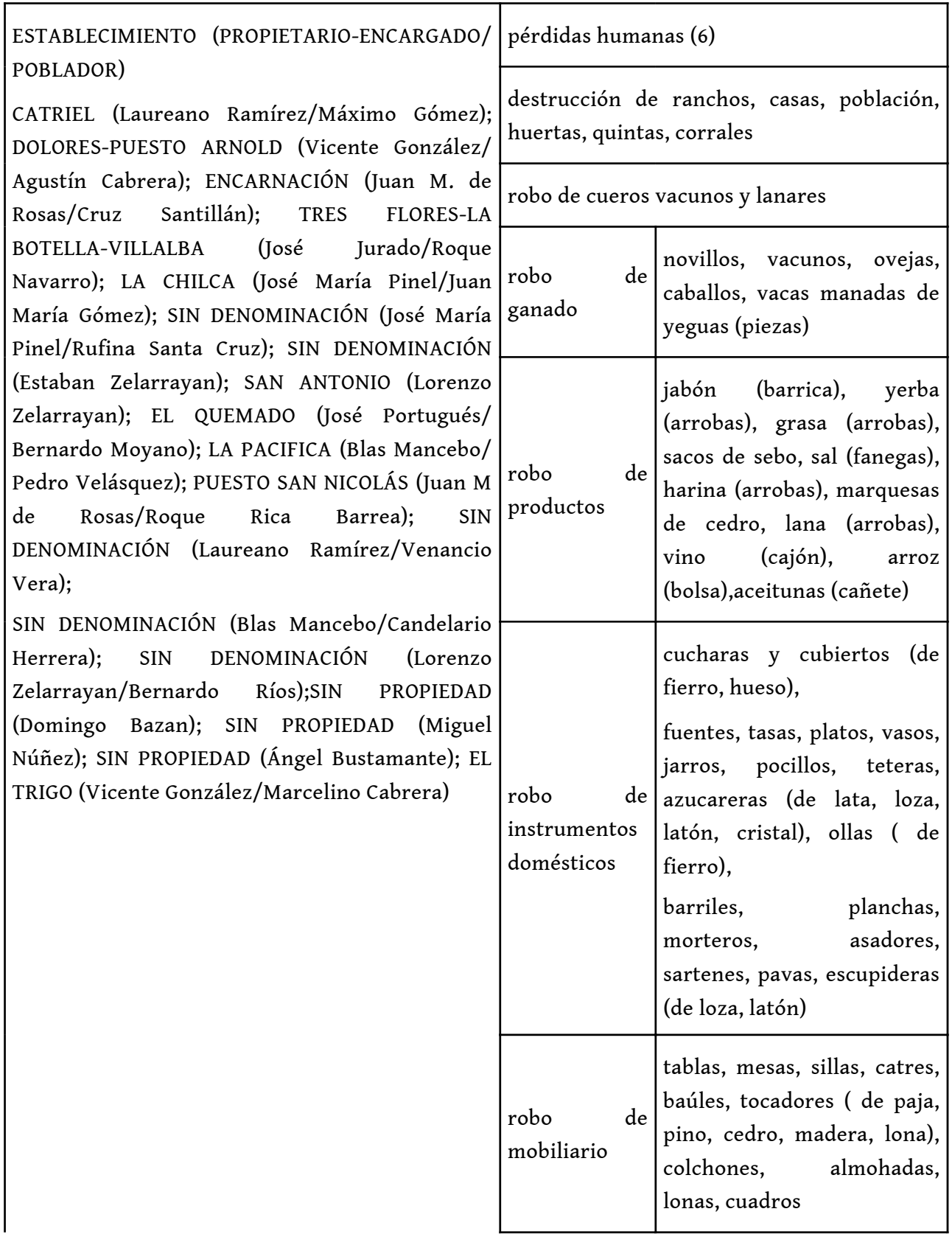




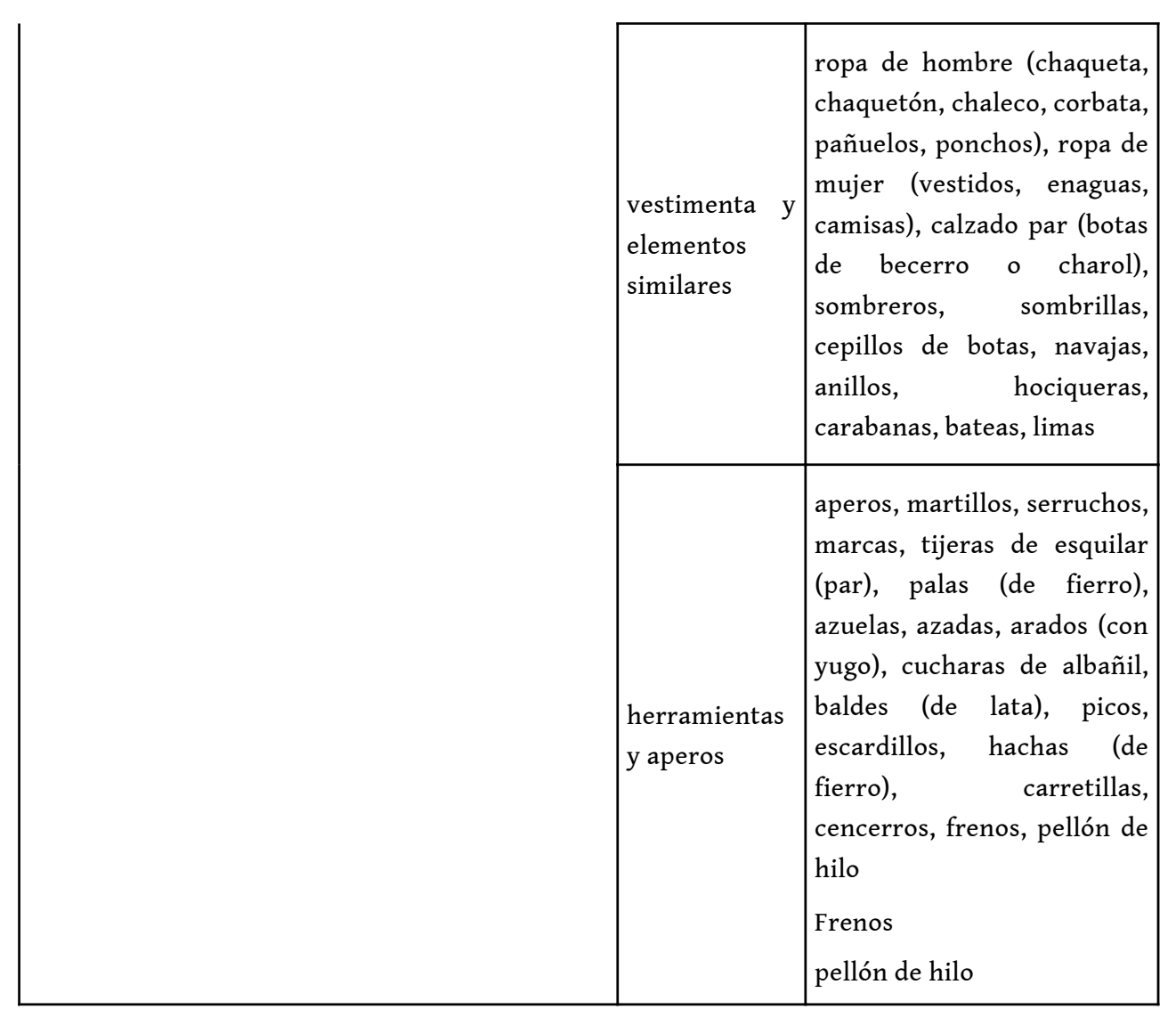

Fuente, AGN, AF, CL, Leg. 266. norte de la provincia e incluían varios puestos, además de medianeros. Según Amaral (1998), tomando el valor promedio de una cabeza de ganado, el valor de una estancia de las mismas dimensiones era un 59\% mayor que a inicios de la expansión ganadera. Y esto fue así porque creció el valor de la tierra y el de las mejoras, mientras que decreció el valor del ganado. ${ }^{30}$ Esta ecuación supuso una excelente oportunidad para extender los negocios en la frontera (Banzato y Lanteri 2007). Sumado a esto, las estancias habían incorporado mejoras. En los registros de contribución directa de 1852 y de 1853 (este último recaudado por los sitiadores), Juan Manuel de Rosas, José Portugués, Laureano Ramírez y Blas Mancebo aparecen como los individuos con mayor capital en ganado y tierras de Las Flores.

\section{La reorganización del sur}

Es necesario pues vencer a los furiosos demagogos unitarios de la Ciudad, castigando de muerte a los indios barbaros a la vez, y mostrar al mundo de lo que somos capaces. 
Luego del triunfo en San Gregorio, Lagos se prestó a intentar pacificar el sur. Allí se encontró con dos problemas relacionados; por un lado, la movilización de las fuerzas que había logrado organizar Pedro Rosas para enfrentar al Ejército Federal. Por otro, la alarma por las incursiones indígenas que amenazaban con atacar a las poblaciones criollas. Si bien la derrota de Pedro Rosas aminoró el peligro, las influencias que, según los sitiadores, tenían los "unitarios" en el sur se mantenían. Como bien llama la atención Ratto (2015, p. 70), la zona en que se concentró la facción pro porteña coincidió con los alineamientos sucedidos durante el levantamiento de los Libres del Sur de 1839, que estudio Jorge Gelman (2002). Para terminar de derrotar a los opositores, los sitiadores tomaron varias medidas conducentes a lograr más y mejor disciplina. En primer lugar, se pactó con algunas parcialidades indígenas y, en segundo, se reorganizaron los juzgados de paz al tiempo que se trabajaba fuertemente para reunir adeptos en los pueblos más reacios a la fracción federal. También se embargaron los campos de los "cabecillas" que apoyaron a la ciudad, se persiguió a los partícipes de la batalla de San Gregorio y se juzgó a Pedro Rosas y Belgrano. En este trabajo nos referiremos solo a los dos primeros puntos. El 31 de enero, desde Dolores, Olmos daba el parte de la situación en el sur:

Aun cuando el Sud se encuentra hoy en prefecta paz y tranquilidad con referencia al movimiento revolucionario; sin embargo no faltan desordenes de robos que los vagabundos derrotados hacen a su tránsito y en los lugares que permanecen afuera. Por lo que es de absoluta necesidad mi marcha al Sud cuando menos a la altura del Durazno o Laguna de los Padres para tranquilizar completamente ese departamento y arreglar las autoridades de esos partidos

Como consecuencia de esto, en su marcha fue destituyendo a los jueces de paz sospechosos: en Tordillo reemplazó a Martín Alzaga con Hipólito Martínez, en Dolores en reemplazo de Pedro Barras puso a Mariano Ramírez y en Pila nombró a Venancio Casalis en reemplazo de Lorenzo Agüero. ${ }^{32}$ Casi de modo paralelo, Lagos le había enviado a Olmos instrucciones sobre las medidas de "pacificación" que debían tomarse en el sur: los nuevos jueces de paz y comandantes debían ser "federales conocidos, honrados y de aptitudes (...) para alejar influencias y lograr conservar el orden". Además, todos los vagos, malentretenidos, desertores o sediciosos debían ser perseguidos y remitidos presos a la Comandancia. El armamento y municiones de los enemigos tenían que ser remitidos a San José de Flores, al igual que las caballadas patrias que no fueran del pago. Por último, se restablecía el pasaporte en toda la provincia. ${ }^{33}$

Olmos respondió a Lagos rápidamente, expresaba que la pacificación ya comenzaba a encaminarse a pesar de ciertos desórdenes generados por los grupos derrotados y "gauchaje que andaba inobediente desde el movimiento de los traidores cabecillas de esos puntos". ${ }^{34}$ Estos, sin embargo, ya habían sido dispersados. Cuatro días después, volvía sobre el asunto de la pacificación y relataba que en Mar Chiquita no había encontrado autoridades civiles por el estado de desorden que existía. Por todo esto, había dejado al Cnel. José Aguilar en Tandil como segundo jefe encargado de la región y desde ese rol Aguilar designaría jueces de paz en Mar Chiquita, Chapaleufú, Bahía Blanca y Patagones. Para mediados de febrero se había reemplazado también a los jueces de Vecino -Damaso Vallido por Juan Antonio Areco-, de Monsalvo y Monte Grande -donde se sacó a Matías Ramos y se designó a Isaías Elías- y de Rincón de Ajo -donde se sustituyó a Martín Campos, uno de los más fervientes apoyos de la ciudad, por Crisóstomo Girado-. El otro 
responsable de la sublevación del sur contra los sitiadores había sido el juez de paz de la Brava, don Juan Ramón Exeiza; este fue depuesto, encarcelado y reemplazado por Eugenio Roballo. Por último, en Chapaleofú fue designado Hipólito Urraco en lugar de Pedro Vela.

El celo y la desconfianza respecto de las fidelidades en el sur eran tan grandes que Lagos solo aprobó los nombramientos efectuados en Dolores y Ajó, mientras que rechazó los de Tordillo, Monsalvo y Vecino por no ser "federales conocidos". Además, dejó en suspenso los restantes por no tener suficiente información. Luego de esto, puso por encima de Olmos a Eugenio del Busto, a quien designó comandante interino del sur. Enterado Olmos del rechazo de Lagos y de la designación de Del Busto, envío al Cuartel General de San José de Flores un nuevo listado de jueces, esta vez de "conocida procedencia federal" y avalados por un hombre de confianza de Lagos, Roque Baudrix. ${ }^{35}$

Los detalles de estas relaciones se nos escapan, pero podemos observar claramente que en medio del conflicto político también aparecían otros problemas de liderazgo o rivalidades personales y también desacuerdos en la organización de la campaña. Conviene no minimizar estas cuestiones, a pesar de no poder ponderarlas de modo exacto.

Toda la correspondencia trabajada describe muy bien el estado de la campaña sur. Esta se encontraba completamente atravesada por la guerra entre los partidarios de la ciudad y del Ejército Federal. La población padecía además todo tipo de problemas debido al reclutamiento de hombres, primero de un bando y luego de otro, la deposición y reposición de funcionarios y el número de haciendas embargadas. Sumado a esto, las matanzas de ganado, los robos, riñas e invasión de los indios tras la batalla de San Gregorio estuvieron a la orden del día.

41 Las incursiones indígenas eran un problema mayúsculo para los sitiadores, puesto que debilitaban la campaña y obligaban a destinar fuerzas del cerco al sur. Debido a esto se envió al sargento Federico Olivencia a Salinas Grandes para una misión de pacificación con Calfucurá, ${ }^{36} \mathrm{y}$ al mismo tiempo se intentó aquietar a los indios de Tapalqué. Estos lentamente devolvían la hacienda que habían robado en los últimos días de enero. Paralelamente, el coronel Eugenio del Busto fue enviado a comandar los partidos de Azul, Tapalqué y Las Flores, mientras Olmos se ocupaba de los restantes partidos de la región. ${ }^{37}$ En correspondencia a este último, Del Busto relataba la situación:

Sigo trabajando para apaciguar a los indios y una buena parte de ellos ya lo han hecho y estan voluntariamente devolviendo las haciendas que se habian robado, vacunos, caballares, lanares. Otra parte de los indios protestando temores se han alejado más alla de la sierra de la Blanca. Es un pretexto para mantener la hacienda que han robado pero pronto se aquietaran y la devolveran. Muchos ya dicen que fueron engañados por P. Rosas [...] Estos partidos pertmanecen perfectamente tranquilos respecto de los cristianos, pero estos con su pequeña desconfianza acerca de los Indios, como es natural por las cosas recientemente pasadas, pero creo, repito, que todo se aquietara y que pronto entraran a tener confianza los Indios en los Cristianos y estos en aquellos, pues el cacique Catriel, Yancatul, Calfiaho, Puiti y Mayca son los que estan entregando las haciendas, que he dicho a U. antes, y estan trabajando de acuerdo conmigo para aquietar a los demas indios, y persuadirlos que entreguen las haciendas. ${ }^{38}$

Recordemos que en Azul y Tapalqué los vínculos entre indígenas y criollos tenían años; desde agosto de 1832 las tribus de los caciques "amigos" Juan Catriel y Juan Manuel Cachul se habían trasladado del establecimiento "Los Cerrillos" de Rosas en Monte para establecerse en el cantón de Tapalqué, a unas leguas del Azul, de forma concomitante a la fundación oficial del fuerte homónimo en diciembre de ese año. ${ }^{39}$ Así, la zona fue el 
asiento territorial de las tribus "amigas" más fieles al rosismo desde comienzos de siglo, y los "catrieleros" no solo fueron poblacionalmente importantes por su número sino que constituyeron parte del vecindario local, participando incluso de las milicias y las elecciones (Ratto 1994, 2003; Lanteri 2008a, 2008b, 2011). Luego de la caída de Rosas, la situación se modificó pero, como este estudio y otros anteriores demuestran, los vaivenes que se produjeron hasta llegar a 1855 fueron muchos y variados.

En otra nota, Del Busto advertía a Lagos sobre la necesidad de entrar en buenos tratos con Calfucurá y Baigorria. Le aconsejaba que se enviaran más chasques $-\mathrm{y}$ obsequios- para informar sobre el estado favorable de la causa federal y, respecto de Baigorria, sugería que:

éste haga saber al Cacique Pichun y demás el estado de nuestra politica y triunfos sobre los enemigos revoltosos a fin de que se contengan las tribus que pudieron haberse alarmado a consecuencia de las ordenes que, según tengo entendido, había dado el Señor Director Provisorio de la Confederación Argentina al mencionado Coronel Baigorria para que amaguen sobre esta parte de la frontera..$^{40}$

El 11 de febrero volvió a escribir para informar sobre las divisiones entre los indios de Tapalqué:

Sigo haciendo el maximo esfuerzo para la pacificacion de los indios de Tapalque y se esta logrando porque estan devolviendo la hacienda. Lo arreglo con los caciques principales Juan Catriel, Juan Manuel Cachul, Yancanecul y Caifiao Viejo. El problema es la relación de estos con los de afuera. Una parte de los indios de Tapalqué que se dice chilenos se fue para Salinas diciendo unos que tienen miedo y otros que fueron llamados por Cafulcurá, y otros por los ranqueles y Baigorria. Puede que algo sea verdad pero yo creo que sobre todo es para marcharse con la hacienda. ${ }^{41}$

La respuesta de Lagos a Del Busto fue escrita el 15 de febrero, allí daba cuenta de varias cosas; en primer lugar, mencionaba el trato pacífico que se mantenía con los indios de Mulitas, Bragado y Federación como la buena predisposición que existía por los servicios prestados..$^{42}$ Luego se explayaba en torno a la situación con los indios de Tapalqué:

El Gral Dn Gregorio Paz desde su venida solo una vez lo he visto y en ella nada me ha hablado referente a indios; ni menos por indicación de U. Sin embargo después de los sucesos de Sn Gregorio tuve un parlameto con los indios y marcharon todos los caciques indios y familias llevando mis palabras a los indios de afuera y solo quedó aquí el Mayor Balcala, un Cacique, un Caciquillo, y cuatro indios esperando (la contestacion) el resultado delos mensageros y (esperar) también la conclusion de estos sucesos y hasta el establecimto de gobno, por lo que ya conocera u. que delos que han quedado (el) no es posible mandar ninguno. Tanto (en) los indios que marcharon, como enlos qehan quedado aqui se advierte la mejor disposicion. Ellos le mandaron a decir a Cafulcura que preparase sus indiadas pa contener alos de Tapalquen y por mi parte los he obligado del modo que me ha parecido mas conveniente para ponerme ya en el caso de pegarles un golpe a esos indios si siguen haciendo daños y no se contienen. El Exmo Señor Director Provisorio mando decirme que Baigorria y Pichun estan de acuerdo con el y le habian ofrecido su cooperacion pa en caso la necesitase [...] Es pues muy conveniente emplear todos los medios pacificos qe $U$. sabe son necesarios pa aquietar esos indios pero si no se consigue tb expreso decirle que estoy muy dispuesto a unirme a Cafulcura, Pichun y demas para contenerlos y ponerlos al dominio de aquellos. Para el efecto ya hepreparado y despertado esta idea enlosotros, quienes como U. sabe no quieren bien a esos indios, y estoy a la verdad muy dispuesto a no consentir, en que estén imponiendo como lo hanacostumbrado. Es pues preciso hacer lo posible pa que dichos indios entreguen las haciendas que se le puedan sacar (haciéndoles entender) que asi solamente se les dara la manutencion que precisan. ${ }^{43}$ 
muestra nuevamente lo complicado y variable de la relación entre los indígenas y los sitiadores y la de los primeros con la Confederación. Aún más, la de las parcialidades indígenas entre sí. Respecto de esto último, la confrontación política generó un campo favorable para la unidad indígena bajo el mando de Calfucurá que cristalizó en los años posteriores, ya con la efectiva separación de Buenos Aires de la Confederación Argentina. Consideramos que esta coyuntura bélica al interior de Buenos Aires terminó siendo una suerte de ensayo, quizás no buscado pero efectivo, para la posterior y explícita acción conjunta. Algo de esto puede observarse en el malón que trabajamos en el apartado siguiente.

\title{
El costo económico del malón de febrero de 1853
}

\author{
Es ya tan general, y es tanto lo qe se ha propagado \\ la vos qe no hay indio ni china qe no diga qe la \\ invasión hecha es por orden del sor Director y de \\ V. S. pues qe asi se lo ha dicho Cafulcurá, Pichum y \\ Baigorria. \\ (Eugenio del Busto a Hilario Lagos, 28 de febrero de \\ $1853)^{44}$
}

La incursión sobre el sur con la que venían amagando los ranqueles se desencadenó finalmente a partir del 12 de febrero de 1853 y a pesar del parlamento celebrado en Leubucó a principios de enero. En menos de un mes las cosas habían cambiado, Baigorria y Pichuiñ organizaron la incursión a Buenos Aires con el propósito de invadir Tapalqué, y Calfucurá se les unió en la marcha. Participaron alrededor de 4.700 lanceros y fue una de las invasiones más grandes del período. Los indios presentaron el malón como una estrategia de Urquiza con apoyo de Baigorria, pero la presencia in situ de este es poco probable puesto que los documentos citan que durante esos días estaba en San Luis (Allende 1957). Esto no invalida que Baigorria haya podido mover influencias aun estando distante. El gobernador de Córdoba, Alejo Guzmán, envió una carta al ministro de Relaciones Exteriores de la Confederación, Luis de la Peña, donde se relatan los dichos de un ex cautivo de los indios "dice que el Coronel Baigorria se haya en la Capital de San Luis con algunos indios". ${ }^{45}$

Lagos, en tanto, no había ordenado el malón sobre los criollos, pero sí había alentado a que se contuviera a los indios de Tapalqué. Sin embargo y en palabras de Eugenio del Busto:

unos indios reciben mensajes del Señor Director Provisorio, otros reciben mensajes de V. S y otros reciben mensajes del Comandante militar de Mulitas y los indios lo que hacen es hacer recaer en los cristianos todo el mal que les es posible hacer, como resulta ahora, después de haber ofrecido contener a los de Tapalqué, ofrecido también su cooperación, resulta que viene a atacar a las vacas y á las yeguas en una parte donde ninguna clase de enemigo hay. ${ }^{46}$

Los ranqueles y salineros no contuvieron a los de Tapalqué, sino que se unieron a algunos de ellos y terminaron asaltando a las poblaciones criollas de la zona.

Lagos se enteró de la invasión recién el 26 de febrero, por conducto del gobernador de Santa Fe, que lo sabía desde el día 17, y por Del Busto. ${ }^{47}$ Esta incursión fue mucho más grave de lo que refleja la bibliografía y provocó un fuerte golpe para la campaña más allá 
de Tandil, Azul y Tapalqué; sobre todo para las estancias de Lobería y Tres Arroyos (ver cuadro 2).

51 Mientras Pichuiñ y Cafulcurá saqueaban el sur, Calvaiñ repartía a sus indios en incursiones sobre la frontera de Córdoba y al norte de la provincia de Buenos Aires, también en Rojas y Salto (Allende 1957, p. 116). Cuando Baigorria volvió de San Luis (10 de marzo), respondió que no sabía de las incursiones y que iba a informar a Urquiza. Días después se encontró con Pichuin y Calvaiñ y, si bien expresaba su desagrado por el malón, planteaba que no tomaría represalias. Luego de esto, en el mes de abril restableció relaciones con los caciques (Allende 1957, p. 117).

Entonces: ¿la orden de invasión fue impartida por Urquiza, o Baigorria terminó actuando bajo sus propios lineamientos junto con otras parcialidades? La cuestión es compleja porque hasta el momento nadie sabe exactamente cómo se organizaban las estrategias indígenas, además de sus vaivenes. Lo que sí parece claro es que la forma de "hacer política" de la sociedad indígena permitía que las diferencias entre "indios amigos" y de "tierra adentro" se dejaran a un lado ante las posibilidad de generar alianzas exitosas contra el control estatal y político de la sociedad criolla. En coyunturas específicas, la resistencia a la dominación terminaba siendo un elemento aglutinante y que definía ecuaciones.

Volviendo a la situación entre las partes en conflicto, el malón no fue un hecho que haya beneficiado a los sitiadores como se denunciaba en Buenos Aires, sobre todo por los daños económicos que generó. No olvidemos que existía un ejército que se abastecía de las estancias de la campaña, sobre todo de las de los "enemigos" y el ganado no era ilimitado. Desde la batalla de Caseros el ganado caballar escaseaba, producto de la demanda de los ejércitos $\mathrm{y}$, sumado a esto, las diferentes disposiciones sobre la matanza de yeguas que se promulgaron en 1852 terminaron por elevar el precio de estos animales. Tan es así que se pagaba por yegua $\$ \mathrm{~m} / \mathrm{c} 10$ en 1851, luego \$ m/c 15 y al promediar el año se llegó a pagar hasta $\$ \mathrm{~m} / \mathrm{c} 20 .{ }^{48}$

En marzo de 1853, Lagos exponía el estado de destrucción en el que había quedado la campaña sur luego del malón y cómo esta situación los perjudicaba gravemente; negaba por tanto su participación y deslizaba la posibilidad de que hubiera sido la ciudad quien fomentara el malón:

Es muy cierto, por otra parte, que emisarios vendidos a los infames enemigos de la Paz y organización Nacional, encerrados en la Capital, se han internado entre las diferentes tribus del Desierto y excitando la propensión al robo y al pillaje de los depredadores, le han mostrado la seguridad que tendrían para sus latrocinios, en la falta de fuerzas que se pudiera oponer; jusgando ellos así causar una disminución de las que asedian la Ciudad. ${ }^{49}$

El cuadro 2 describe pormenorizadamente los reclamos de los estancieros luego del malón de febrero de 1853. Las casi 200.000 cabezas de ganado denunciadas dan cuenta de la trascendencia de esta incursión.

CUADRO 2 
“Relación de los daños causados por los indios de Quequén Grande afuera; según los partes recibidos por el Sargento Mayor Dn Manuel García y el Juez de Paz Dn Benigno Acosta. Firma: José Aguilar"

\begin{tabular}{|c|c|c|c|c|}
\hline \multirow{2}{*}{ Dueño } & \multicolumn{3}{|c|}{ hacienda ( $\mathrm{N}^{\circ}$ de cabezas) } & \multirow{2}{*}{ negocio } \\
\hline & Vacuno & Yeguarizo & Lanar & \\
\hline Medialuna de & 3.300 & 1.000 & 2.000 & 80.000 \\
\hline Fernando Pando & 0 & 0 & 0 & 8.000 \\
\hline Manuel Savino & 1.500 & 800 & 0 & 50.000 \\
\hline Juana Caseres & 3.000 & 0 & 0 & 0 \\
\hline Asencio Orellanos & 2.000 & 0 & 0 & 0 \\
\hline Caseres & 8.000 & 0 & 0 & 0 \\
\hline Francisco Paz & 1.000 & 0 & 0 & 0 \\
\hline Los pobres & 10.000 & 0 & 0 & 0 \\
\hline Alfonso & 5.000 & 0 & 0 & 0 \\
\hline Francisco Bosch & 20.000 & 5.000 & 0 & 0 \\
\hline Guerrico & 15.000 & 0 & 0 & 0 \\
\hline Irola & 15.000 & 0 & 0 & 0 \\
\hline Jose Maria Martínez & 1.000 & 0 & 0 & 0 \\
\hline Feliciano Hernandez & 1.500 & 2.000 & 0 & 0 \\
\hline Nicolas Avalos & 1.400 & 0 & 0 & 0 \\
\hline Pacheco & 3.500 & 700 & 0 & 0 \\
\hline Alberto Marquez & 3.000 & 50 & 0 & 0 \\
\hline Mariano Villalba & 3.000 & 2.000 & 0 & 0 \\
\hline Sesano Cristiano & 10.000 & 2.000 & 0 & 0 \\
\hline Eusebio Funes & 400 & 200 & 0 & 0 \\
\hline Pedro Vega & 1.180 & 500 & 0 & 0 \\
\hline Cornelio Gimenez & 30 & 40 & 0 & 0 \\
\hline Mendiburo y $\mathrm{Ca}$ & 12.500 & 2.500 & 0 & 100.000 \\
\hline
\end{tabular}




\begin{tabular}{|l|l|l|l|l|}
\hline Vicente Igarzabal & 3.600 & 1.500 & 0 & 0 \\
\hline Elias Galvan y la viuda Marta & 3.550 & 400 & 0 & 0 \\
\hline Mauricio Solera y Manuel Martinez & 1.750 & 1.130 & 0 & 0 \\
\hline Ignacio Salguero y Cosme Puchol & 4.300 & 1.600 & 0 & 0 \\
\hline Coria y Arana & 5.200 & 1.150 & 0 & 0 \\
\hline Antonio Cordoba & 2.350 & 1.000 & 0 & 0 \\
\hline Juan Zarate y Figueroa & 2.850 & 2.020 & 0 & 0 \\
\hline Luciano Medina y Pancho Paz & 4.200 & 1.250 & 200 & 0 \\
\hline La viuda Juana & 4.350 & 1.700 & 0 & 0 \\
\hline Orellano, Caseres y el Vasco & 2.600 & 2.900 & 0 & 0 \\
\hline Barraza & 2.200 & 0 & 0 & 0 \\
\hline Justo Alfonso y Anastasio Giles & 2.760 & 1.310 & 0 & 0 \\
\hline de varios individuos de los que no se les sabe el nombre & 900 & 1.000 & 0 & 0 \\
\hline Total & 161.920 & 33.750 & 2.200 & 238.000 \\
\hline
\end{tabular}

Fuente: AGN, AF, CL, Leg. 266.

A primera vista la cantidad de ganado robado parece abultadísima pero, si observamos la densidad de población del sur proclive a integrar un malón, la situación no parece imposible. Contamos con el importantísimo informe que realizó Pedro Rosas y Belgrano sobre la población indígena sostenida por el Gobierno de Buenos Aires en el período inmediatamente anterior al sitio. Si bien no todas las parcialidades integraron el malón de febrero, el informe nos permite darnos una idea de la densidad del mundo fronterizo de esos años.

\section{CUADRO 3}

Planilla que manifiesta aproximadamente el número de Indios en familia, mansos, que existen en la Provincia y que son sostenidos por el Superior Gobierno. 13 de octubre de 1852. Firma: Pedro Rosas

\begin{tabular}{|l|l|l|l|}
\hline Puntos donde existen & $\begin{array}{l}\text { Nombres de los } \\
\text { caciques }\end{array}$ & $\begin{array}{l}\text { Indios de } \\
\text { pelea }\end{array}$ & $\begin{array}{l}\text { Número } \\
\text { familias }\end{array}$ \\
\hline Tapalqué & Catriel de & 8.000 & 24.000 \\
\hline Salinas Grandes & Calfucurá & 800 & 2.400 \\
\hline
\end{tabular}




\begin{tabular}{|l|l|l|l|}
\hline Salinas Grandes & Paque Nancú & 300 & 900 \\
\hline Salinas Grandes & Llusquen & 400 & 1.200 \\
\hline Salinas Grandes & Unaiche & 150 & 450 \\
\hline Salinas Grandes & Chuguiquen & 300 & 900 \\
\hline Bahía Blanca & & 100 & 300 \\
\hline Patagones & & 900 & 2.700 \\
\hline Mulitas & & 50 & 150 \\
\hline Federación & & 50 & 150 \\
\hline Bragado & & 50 & 150 \\
\hline $\begin{array}{l}\text { Total de indios de clanza" y } \\
\text { "chusma" }\end{array}$ & & 1.500 & 4.500 \\
\hline Ranqueles y Borogas & & 33.300 \\
\hline
\end{tabular}

Fuente: AGN, Estado de Buenos Aires, Gobierno, 1852. Mencionado también por Allende (1957, p. 65).

57 A modo de ejemplo, en 1852 se les suministraba a los indios de Tapalqué y Salinas alrededor de 2.500 yeguas por mes que venían en número de a 200 o 300 desde Las Flores, Monte, Ranchos, Chascomús, Tordillo, Ajó, Tuyú, Vecino, Pila, Chapaleofú, Mar Chiquita y Lobería. ${ }^{50}$ En el transcurso de noviembre, mes previo a la rebelión federal, no se detuvo el suministro puesto que fueron entregadas en Azul la cantidad de 1.369 yeguas para los indios amigos. ${ }^{51}$ Incluso en diciembre se enviaron cabezas desde Tuyú, Pila y Vecino. ${ }^{52}$

La cantidad de yeguarizos robados durante el malón implicaba asegurarse el suministro por más de un año. ${ }^{53} \mathrm{Y}$ esto sin contar el ganado vacuno sustraído, que de ser ciertas las cifras representó el 5,4\% del total de cabezas existentes en la provincia al iniciar la década de $1850 .{ }^{54}$ En relación con los ovinos, el impacto fue muchísimo menor. Si calculamos además el costo en términos monetarios, la pérdida económica fue de \$F 350.996, descompuestos de la siguiente manera:

\section{CUADRO 4}

Robos y daños denunciados en pesos fuertes ${ }^{55}$

\begin{tabular}{|l|l|l|}
\hline Rubros & $\$ \mathrm{~F}$ & \$ por cabeza \\
\hline Vacunos & 301.171 & 1,86 \\
\hline Yeguarizos & 33.750 & 1 \\
\hline Lanares & 1.320 & 0,6 \\
\hline
\end{tabular}




\begin{tabular}{|l|l|l|}
\hline negocios comerciales & 14.755 & \\
\hline Total & 350.996 & \\
\hline
\end{tabular}

Fuente: AGN, Estado de Buenos Aires, Gobierno, 1852. Mencionado también por Allende, A., 1957, p. 65.

Por supuesto que esto es un costo estimativo, puesto que no sabemos de manera certera si la cantidad de ganado denunciado fue de tal envergadura y, por el contrario, deben haber quedado fuera del recuento los robos que no fueron denunciados ya sea por la escasa magnitud del daño o por otras razones. Más allá de estas precauciones, los testimonios y la historiografía han dado por ciertas estas cifras, cuestión que nos faculta para establecer las relaciones que se han señalado.

60 Además del robo de ganado, se denunciaron 14 cautivos y 10 muertos, la quema de ranchos y de casas. El trayecto que hicieron los indios incluyó Cristiano Muerto, Tres Arroyos, donde saquearon la estancia "la Rosa del Sud", y también el Paso del Médano, donde los testigos denunciaban haber visto alrededor de 800 indios mayoritariamente de Tapalqué. El 28 de febrero se encontraban sobre el arroyo de Napostá (Bahía Blanca) y por el Sauce Grande (Monte Hermoso). En este último paraje se vieron alrededor de 50 o 60 indios que arrebataron 200 yeguadas de los establecimientos de Marcos Toledo, donde además asesinaron a un peón. De allí se dirigieron al puesto "de Benítez" donde quemaron los ranchos y se llevaron las yeguas y los caballos. Pasaron luego al establecimiento de don Manuel Bentos y allí arrebataron cuatro tropillas de caballos. ${ }^{56}$ Finalmente desde Tres Arroyos se trasladaron a las tolderías de Carhué.

\section{La misión Olivencia}

61 El sargento Olivencia partió a Salinas Grandes para la misión de pacificación a fines de enero. Al llegar no pudo encontrarse con Calfucurá porque el cacique hacía diez días que se había marchado al Quequén Grande junto con Pichuiñ. En ausencia del cacique, el enviado quedó en una situación muy desfavorable, "cuasi" cautivo, vigilado, sin ropas ni vicios. ${ }^{57}$ Finalmente Calfucurá regresó a la toldería de Atrencó el 12 de marzo, allí manifestó que la orden de desatar el malón la habían dado Urquiza, Lagos y Paz por conducto de Baigorria. Olivencia, según instrucciones, negó tal orden y culpó a Baigorria de hablar en nombre del Director (Allende 1957, p. 123). Anoticiado de esto, Calfucurá habría cambiado su actitud y, según olivencia, se dispondría a negociar con los sitiadores:

No encuentro en el Cacique Calfucurá la mas pequeña culpa en esta invasión al contrario; a prestado en esta ocasión un servicio de grande importancia a nuestra provincia privando se matase y sugetando a sus ordenes la mayor parte de esos Indios de Tapalquéqe eran los que estaban causando grandes perjuicios en los partidos de Las Flores, Saladillo y Leoncho y demás puntos hallándose hoy estos en el mayor sosiego. Estacionados en el Sauce Grande a las órdenes del Cacique Calfucurá y el resto que queda al mando del cacique Gral Lefí Pichun se acaba de saber en este momento por medio de unos chasques, qe se dirige hacia estos destinos a ponerse en tratados con el Cacique Gral Calfucurá. ${ }^{58}$

62 Agregaba que a pesar de que el Gobierno [separatista] culpaba de los destrozos a los indios de Tapalqué, 
no es asi pues dicho Cacique con la gente que se ha mantenido a su lado no ha cometido el mas leve daño ni robado un solo animal, lejos de ello completamente a pie y el resto qe hoy se halla en el Sauce Grande y que está a las ordenes del Cacique Calfucurá (que son los que han robado, han sido indusidos y aconsejados fuertemente por el salvaje Pedro Rosas, mandándole que robasen matasen y cautivasen para ayudarle de este modo a su descabellada empresa por lo cual en vista delo que expongo a VS juzgará aquello más exacto según los conocimientos que puede VS tener de otros Gefes. ${ }^{59}$ separatismo porteño y las tropas federales de la campaña como parte de las potenciales fuerzas militares de los ejércitos en guerra; pero, además de esto, el peso de su accionar se vio acrecentado puesto que en esta coyuntura bélica elaboraron sus propias estrategias de guerra y resistencia, aprovechando las disidencias de modo conjunto. Así, el margen de autonomía en la acción que, aún bajo control del Estado, tuvieron los "indios amigos" no fue despreciable como quedó en evidencia tanto en la batalla de San Gregorio como en el malón de febrero de 1853. Las acciones de este año permitieron quizás que se apreciara en el campo indígena las posibilidades de daño que tenían las acciones conjuntas. Las razones fueron varias: el conflicto provocó la desatención de la frontera, suspendió el suministro de "vicios" y modificó tanto como fragmentó a los interlocutores que negociaban con los indígenas: separatistas, sitiadores y confederados. Todo esto generó que en 1853 las relaciones con las parcialidades fueran inestables y favoreció la gestación del malón de febrero sobre el sur de la campaña bonaerense. Esto puso de manifiesto también la amplia red de comunicación con la que contaban los indígenas y las alianzas que podían generarse. Las consecuencias económicas para el sur fueron tremendas: pérdida de ganado, ya de por sí escaso, de riqueza y de vidas. Según los partes de los funcionarios, la población estaba aterrada por las incursiones indígenas y la inseguridad era moneda corriente, puesto que las milicias estaban destinadas al cerco porteño y los pueblos eran defendidos con mínimas partidas.

Volviendo al accionar indígena, con las precauciones del caso, proponemos algunas explicaciones parciales. Los indios amigos de Azul y Tapalqué venían de una larga y personal relación con Juan Manuel de Rosas, que ya fue mencionada. Los meses que siguieron a la batalla de Caseros fueron una vorágine y completamente inestables. La 
debilidad institucional producto de las luchas intestinas en Buenos Aires parece haber provocado la suspensión periódica de raciones durante diciembre y enero, y esto generó malestar. Por otra parte, la guerra fue un acontecimiento que generó modificaciones en las alianzas y un contexto propicio para estrategias de resistencia o, al menos, de búsquedas de "nuevos equilibrios" entre los grupos de dentro y fuera de la frontera, que al mismo tiempo actuaban con cierta autonomía entre ellos.

Desatada la rebelión rural del $1^{\circ}$ de diciembre, Pedro Rosas y Belgrano, con largo arraigo e influencia en los pagos del sur, logró reunir a los indios amigos para sus filas. No obstante, esta adhesión no fue permanente puesto que, como ya relatamos, luego de parlamentar con los indios amigos de Collinao que participaron del lado sitiador, los de Azul desertaron y saquearon las poblaciones que se encontraban camino a sus toldos. Se impone entonces una reflexión: la alianza entre los indios de Azul y Tapalqué y el Estado de Buenos Aires no fue lo suficientemente fuerte ni definitiva para enemistarlos con otras parcialidades ni para impedirles beneficiarse de la frontera alzándose con bienes y ganado.

Esta situación generó varias reacciones; por un lado, los enemistó con el Gobierno de la ciudad que se sentía "traicionado", por otro, generó una nueva relación con los sitiadores que, sin embargo, fue de mutua desconfianza. El hecho de desertar de las tropas de Pedro Rosas los acercó a los sitiadores, pero el terrible malón que realizaron luego generó enemistad y problemas con los vecindarios afectados. Debido a esto, los sitiadores les pedían que devolvieran la hacienda, se mantuvieran tranquilos y reacomodaran su relación en los pueblos. Para eso no solo se envió a los principales jefes, también se destinaron emisarios para informar a los indios "de afuera" (aliados a la Confederación) sobre los triunfos del Ejército Federal y sobre las desavenencias con los indios de Tapalqué. De esta manera, Lagos dejaba abierta la posibilidad de que fueran salineros o ranqueles los que disciplinaran a estos indígenas. Segunda reflexión, el ejército sitiador se sirvió de las relaciones entabladas entre el líder de la Confederación y los indios "de afuera" para intentar controlar a los indios de "dentro". La situación se complejiza aún más si tenemos en cuenta que la diplomacia indígena operó paralelamente hacia adentro y elaboró sus propias estrategias, tal cual expusimos.

69 Por último, la derrota de los separatistas en San Gregorio junto con la toma de prisioneros posterior, incluido Pedro Rosas y la oficialidad, desarticuló las posibilidades de derrotar el sitio desde la campaña. Los defensores de la ciudad, como se autodenominaban, tuvieron que buscar nuevas alternativas para lograr desarmar el cerco que se cernía sobre Buenos Aires; estas incluyeron intentos de paz (fracasados) y, finalmente, intentos por derrotar el bloqueo naval. Situación que finalmente se logró en julio de 1853.

\section{BIBLIOGRAPHY}

Fuentes

Archivo General de la Nación 
Archivo de Urquiza

Archivo Farini, Correspondencia Lagos

Estado de Buenos Aires

Gobierno Nacional, Sección Gobierno, Subdivisión Guerra. Comandantes de los Departamentos Norte y Sud.

Archivo Histórico de la Provincia de Buenos Aires.

Juzgados de Paz

Archivo Histórico de la Provincia de Santa Fe.

Estado Mayor del Ejército, División VII, Campaña contra los indios.

Allende, A. (1957). La Frontera y la Campaña del Estado de Buenos Aires (1852-1853). La Plata: UNLP.

Amaral, S. (1998). The Rise of Capitalism on the Pampas. Cambridge: Cambridge University Press.

Barcos, M. F. (2012). Expresiones políticas y movilización popular en los pueblos de la campaña de Buenos Aires. La Guardia de Luján y el Sitio de Lagos (1852-1854). Nuevos Mundos, Mundos Nuevos, (12). En: http://nuevomundo.revues.org/62504

Barcos, M. F. (2017). Política y trincheras. Los pueblos en la organización del Ejército Federal a inicios del sitio a la ciudad de Buenos Aires, diciembre de 1852-febrero de 1853. En R. Falcón y R. Buve (Eds.), Pueblos en tiempos de guerra, (pp. 51-80). Ciudad de México: COLMEX.

Banzato, G. y Lanteri, S. (2007). Forjando la frontera. Políticas públicas y estrategias privadas en el Río de la Plata, 1780-1860. Historia Agraria, XVII (43), 435-458.

Bechis, M. (2002). La “organización nacional” y las tribus pampeanas en Argentina durante el siglo XIX. En A. Escobar Ohmstede, R. Falcón y R. Buve (Comps.), Pueblos, comunidades y municipios frente a los proyectos modernizadores en América Latina, siglo XIX, (pp. 83-106). Países Bajos y México: CEDLA Latin American Studies /El Colegio de San Luis, A.C.

Bechis, M. (2008). Cacicazgos pampeanos: fronteras adentro, fronteras afuera. Revista TEFROS, 6 (1).

Caletti Garciadiego, B. (2014). Después de la tormenta ¿la calma?: Ejército y Milicias en la campaña porteña tras Caseros. Coordenadas. Revista de Historia Local y Regional, I (1), 59-89.

Canciani, L. (2014). "Es preciso, pues, regimentar": La organización de la Guardia Nacional de campaña. Buenos Aires, 1852-1862. Anuario del Instituto de Historia Argentina, (14). En: http:// www.memoria.fahce.unlp.edu.ar/art_revistas/pr.6724/pr.6724.pdf

Cárcano, R. (1946). De Caseros al 11 de septiembre: 1851-1852. Buenos Aires: Mendesky.

Cutrera, M. L. (2013). “Que todavía no se ha acabado esto”. Sobre el fin del Negocio Pacífico de Indios después de Caseros. Anuario del Instituto de Historia Argentina, (13), 125-156.

Di Meglio, G. (2013). La participación política popular en la provincia de Buenos Aires, 1820-1890. Un ensayo. En R. Fradkin y G. Di Meglio (Comps.), Hacer política. La participación popular en el siglo XIX rioplatense, (pp. 273-304). Buenos Aires: Prometeo.

Gelman, J. (2002). La rebelión de los estancieros. Algunas reflexiones en torno a los Libres del Sur de 1839. Entrepasados, (22), 113-144.

Foerster, R. y Vezub, J. (2011). Malón, ración y nación en las pampas: el factor Juan Manuel de Rosas (1820-1880). Historia, II (44), 259-286. 
Gelman, J. y Santilli, D. (2015). Salarios y precios de los factores en Buenos Aires, 1770-1880: una aproximación a la distribución funcional del ingreso en el largo plazo. Revista de Historia Económica, XXXIII (1), 153-186. En: http://journals.cambridge.org/abstract_S0212610915000075

Garavaglia, J. C. (2007). De Caseros a la guerra del Paraguay: el disciplinamiento de la población campesina en el Buenos Aires posrosista (1852-1865). En Construir el estado, inventar la nación. El Río de la Plata, siglos XVIII-XIX, (pp. 311-342). Buenos Aires: Prometeo.

Lanteri, S. (2011). Un vecindario federal. La construcción del orden rosista en la frontera sur de Buenos Aires (Azul y Tapalqué). Córdoba: CEH.

Ortiz, R. (1955). Historia económica de la Argentina. Buenos Aires: Raigal.

Pérez Zavala, G. (2007). La política interétnica de los ranqueles durante la segunda mitad del siglo XIX. Quinto Sol, (11), 61-89.

Ratto, S. (2003). Una experiencia fronteriza exitosa: el negocio pacífico de indios en la provincia de Buenos Aires (1829-1852). Revista de Indias, LXIII (227), 191-222.

Ratto, S. (2015). Redes políticas en la frontera bonaerense 1836-1873: crónica de un final anunciado. Bernal: Universidad Nacional de Quilmes.

Scobie, J. (1964). La lucha por la consolidación de la nacionalidad argentina 1852-1862. Buenos Aires: Hachette.

\section{NOTES}

1. Conglomerado de personajes antaño vinculados al unitarismo (exiliados, miembros de la generación del 37, liberales) y también ex rosistas.

2. Luego de los resultados de la batalla, la ciudad fue escenario de desmanes y robos en los que participaron un conjunto variado de sectores (ver Di Meglio 2013). Luego de algunos días de descontrol, Urquiza retomó el control de la ciudad y envió a fusilar a quienes se encontraban delinquiendo. El espectáculo de los fusilados colgados de los postes del camino de Palermo (residencia de Urquiza) parece haber causado sensación. Otro símbolo que molestó a los porteños fue ver a las tropas federales de Urquiza desfilar por las calles de Buenos Aires con el cintillo punzó. Este era una cinta de color rojo utilizada como distintivo federal. Para el Ejército vencedor era parte de la simbología del federalismo en sentido amplio, pero en la ciudad de Buenos Aires era visto solo como un resabio de la denominada tiranía rosista.

3. AGN, Archivo Farini, Correspondencia Lagos (en adelante AF, CL), Leg. 262, $1^{\circ}$ de diciembre de 1852.

4. Para una discusión detallada sobre la función del malón, ver Foerster y Vezub (2011, pp. 259-286).

5. La figura de Pedro Rosas y Belgrano es sumamente importante, hijo de Manuel Belgrano, fue posteriormente adoptado por Juan Manuel de Rosas. Reunía dos condiciones fundamentales para las redes de poder de la época: era militar y hacendado; además integró la Legislatura provincial. Luego de la caída de Rosas, siguió siendo el juez de paz de Azul, por orden directa de Urquiza. Posteriormente, por orden del comandante del sur, el Gral. Hilario Lagos, fue nombrado comandante del Regimiento de Caballería Número 11, con sede en Azul. Cuando estalló la rebelión de Lagos, estaba en la ciudad de Buenos Aires donde decidió participar del lado porteño. La compleja trama de relaciones entre la oficialidad continúa durante toda la década posterior a Caseros y actualmente la estamos analizando.

6. AGN, Sección Gobierno. S. X-4-8. 13 de octubre de 1852.

7. AGN, Sección Gobierno. S. X-4-8. 13 de octubre de 1852. 
8. Se enviaban para Tapalqué y Salinas aproximadamente 2.500 yeguas por mes desde Las Flores, Monte, Ranchos, Chascomús, Tordillo, Ajó, Tuyú, Vecino, Pila, Chapaleofú, Mar Chiquita y Lobería. AGN, Sección Gobierno. S. X-4-7. 14 de abril de 1852.

9. AGN, Sección Gobierno. 13 de octubre de 1852.

10. El caso de Olmos difiere de la mayoría de los otros jefes del movimiento que habían construido su carrera en las filas federales. Si bien había participado con Juan M. de Rosas de la Campaña de 1833, en 1839 se pronunció contra él en apoyo a Lavalle. En el conflicto que estamos analizando apoyó a Lagos y luego continúo sirviendo a Urquiza.

11. Sobre las motivaciones que llevaron a Lagos a iniciar la rebelión desde allí, ver Barcos (2012).

12. El 8 de marzo de 1852 se creó la Guardia Nacional en la provincia de Buenos Aires por decreto del gobernador interino, Vicente López y Planes. Luego de esto, el 17 de marzo, se decretó la disolución de todos los regimientos de milicias de la ciudad y la campaña, a la vez que se ordenó a los ciudadanos que los integraban presentarse al alistamiento para organizar la Guardia Nacional. La organización de las GN fue lenta, pero para mediados de 1852 la campaña ya contaba con 15 regimientos de GN con sus respectivos jefes. Sobre el tema, ver Macías (2001); Caletti (2010); Canciani (2014).

13. Registro Oficial de la Provincia de Buenos Aires, decreto del 6 de diciembre de 1852, pp. 221-222.

14. Contaba con 12 batallones de infantería de línea y Guardia Nacional, artillería de seis baterías de campaña y dos regimientos de caballería. También contaban con una flota de barcos preparados para la guerra.

15. La figura de Eugenio del Busto también es importante para entender las lógicas entre la población y la oficialidad; en 1852 actuaba como comandante del cantón de Bragado puesto que había sido designado allí por sus relaciones con los indios boroganos. Sin embargo, los meses anteriores al sitio, Lagos, en su rol de comandante del sur, lo llamó a la frontera sur. Cuestión que no llama la atención, puesto que conocía la zona por su rol en la formación del fuerte de Tapalqué.

16. Comandante del campamento de Santos Lugares y edecán de Juan Manuel de Rosas durante su gobierno, se opuso desde el principio al movimiento del "11 de Septiembre" y a fines de diciembre se unió a Hilario Lagos. Una de las principales funciones que ejerció durante el sitio consistió en mediar con las fuerzas que reunía Pedro Rosas y Belgrano en el sur.

17. AGN, AF, CL, Leg. 262, 23 de diciembre de 1852.

18. AGN, AF, CL, Leg. 262, 25 de diciembre de 1852.

19. AGN, AF, CL, Leg. 263, 19 de enero de 1853.

20. AGN, AF, CL, Leg. 263, 5 de enero de 1853.

21. AGN, AF, CL, Leg. 263, 10 de enero de 1853.

22. Según Pérez Zavala (2007, p. 66) luego de la muerte de Painé y la caída de Rosas estos caciques desplegaron políticas opuestas. Mientras Calbaiñ atacaba la frontera cordobesa, Pichún negociaba con la Confederación y, unido a Calfucurá, invadiría el sur de Buenos Aires.

23. Juan Bautista Ferreyra a Gerónimo Yofre. Archivo Histórico de la Provincia de Santa Fe, Estado Mayor del Ejército, División VII, Campaña contra los indios. Correspondencia, 6 de enero de 1852.

24. Juan Bautista Ferreyra a Baigorria. Archivo Histórico de la Provincia de Santa Fe, Estado Mayor del Ejército, División VII, Campaña contra los indios. Correspondencia, 6 de enero de 1852. 25. El 19 de enero el comandante de Bragado le informaba a Lagos que los indios de Cafulcurá y Baigorria estaban planeando atacar Tapalqué. AHPBA, JDP de Bragado, Silva, Vicente a Lagos, Hilario, 19 de enero de 1853.

26. Boletín Oficial, 14 de enero de 1853.

27. AGN, AF, CL, Leg. 264, 22 de enero de 1853.

28. AGN, Estado de Buenos Aires, Gobierno, Leg. 31, Doc. 8085. 
29. AGN, AF, CL, Leg. 266, 11 de febrero de 1853, n 271.

30. Las diferencias regionales son importantes pero la disparidad entre la estructura de capital de las estancias de 1820 y las de 1850 es mucho más significativa que las diferencias entre las regiones, a excepción que se compare las zonas de más antiguo asentamiento con las zonas fronterizas. Ver Amaral (1998, p. 49).

31. AGN, AF, CL, Leg. 267, 17 de marzo de 1853, $n^{\circ} 63$.

32. AGN, AF, CL, Leg. 265,31 de enero de $1853, n^{\circ} 272$

33. AGN, AF, CL, Leg. 265,5 de febrero de $1853, n^{\circ} 102$

34. AGN, AF, CL, Leg. 265. 4 de febrero de 1853, $n^{\circ} 98$.

35. AGN, AF, CL, Leg. 265. 14 de febrero de 1853. En Tordillo, Santos Mendoza; en Monsalvo, Apolinario Bellido; en Vecino, Leocordio Vázquez; en Mar Chiquita, Manuel Saavedra; en Lobería, Manuel García; en Chapaleofú, Hipólito Urraco.

36. Llegó el 23 de febrero cuando ya el malón de febrero se había desatado y por esa circunstancia Cafulcurá no se encontraba. Lo tomaron de rehén un par de días, pero finalmente pudo enviar un emisario a informar a Eugenio del Busto de la situación. Ver Allende (1957, pp. 120-121).

37. AGN, AF, CL, Leg. 265, 4 de febrero de 1853.

38. AGN, AF, CL, Leg. 265, 8 de febrero de 1853. Para tener una dimensión del volumen de la hacienda robada, el 11 de febrero los indios de Catriel y Yanquenecul devolvían 2.500 cabezas de ganado. Y aún quedaban vacas, terneros y caballos. AGN, AF, CL, Leg. 265, 11 de febrero de 1853.

39. Dicho fuerte fue establecido sobre el área ocupada previamente por las tolderías del cacique chileno Venancio Coñuepan, quien migró al sur para establecerse en Bahía Blanca dado el gran crecimiento demográfico del pueblo de Azul, que estaba "invadiendo las tolderías" hacia 1832 (Lanteri 2011).

40. AGN, AF, CL, Leg. 265, 8 de febrero de 1853.

41. AGN, AF, CL, Leg. 265, 11 de febrero de 1853.

42. AGN, AF, CL, Leg. 265, 11 de febrero de 1853. La existencia de población indígena en el oeste de la frontera se remonta a la década de 1840, cuando el cacique Collinao (Boroga) con sus indios de pelea abandonó Bahía Blanca para integrarse como compañía de indios amigos en el regimiento del Cnel. Aguilera por la zona de Azul. El grupo se instaló en el pueblo de Bragado en el año 1846, allí se incorporaron los jefes Melinao y Reilef, a quienes se les repartieron solares cuando se hizo la traza del pueblo. Participaron en la batalla de Caseros como escuadrón de indios amigos y apoyando el sitio (Ratto 2015, p. 69).

43. AGN, AF, CL, Leg. 265, 15 de febrero de 1853.

44. AGN, Archivo Urquiza, 28 de febrero de 1853.

45. AGN, Archivo de Urquiza, 20 de febrero de 1853.

46. AGN, AF, CL, Leg. 266, 26 de febrero de 1853.

47. El 26 de febrero, Del Busto se dirige a Lagos para decirle que los indios invadieron por el arroyo Cristiano Muerto y Tres Arroyos encabezados por Cafulcurá con Pichuiñ, Baigorria y los indios de Tapalqué. Todos hicieron causa común desobedeciendo a Urquiza y a Lagos, pero expresando que actuaban en nombre de ellos. Ver Allende (1957, pp. 114-115) y AGN, Archivo de Urquiza, 20 de febrero de 1853.

48. La matanza de yeguas había sido prohibida durante el gobierno de Rosas, pero durante el interregno de Vicente López se declaró libre. En junio nuevamente se modificó la normativa y se otorgó una franquicia por seis meses (de febrero a julio). Los hacendados calculaban alrededor de un millón de yeguarizos alzados que dificultaban las tareas rurales. Debido a esto, y al fracaso de los permisos, en octubre de 1852 se declaró nuevamente libre la matanza. Esta situación generó el alza del precio de los animales (Allende 1957, p. 59). El precio de los caballos también aumentó; cuestión relacionada con el descenso del stock (Garavaglia 2007, p. 338).

49. AGN, AF, CL, Leg. 266, 17 de marzo de 1853. 
50. AGN, Gobierno Nacional, Sección Gobierno, Subdivisión Guerra. Comandantes de los Departamentos Norte y Sud. Abril de 1852.

51. AGN, Estado de Buenos Aires, Gobierno, 1852, Doc. 1970.

52. AHPBA, JDP de Azul, 1852-1853.

53. AGN, Gobierno Nacional, Sección Gobierno, Subdivisión Guerra. Comandantes de los Departamentos Norte y Sud. Abril de 1852.

54. Se estima un stock de tres millones de vacunos y 15 millones de ovinos en Buenos Aires para 1850 (Ortiz 1955).

55. El cambio en 1852 es igual a $\$ \mathrm{~F} 1=\$ \mathrm{~m} / \mathrm{c} 16,13$. Para precios del ganado, véase Allende (1857); Garavaglia (2004); Sabato (1989) y Gelman y Santilli (2015).

56. AGN, AF, CL, Leg. 266, febrero de 1853.

57. “mi posición aquí es de las más terribles a mas de estar expuesto mi vida a cada instante me hallo completamente desnudo, pues todo lo que trahia me lo hn pedido a términos de estar con lo puesto, y esto lo peor qe trahía, todo esto lo ha hecho el mismo cacique, enquien creía estar apoyado, a mas de esto no tengo yerba, azúcar ni tabaco hace mas ocho días único consuelo en estos destierros". Olivencia al Cnel. Mariano Espinoza, AGN, AF, CL, Leg. 267, marzo de 1853.

58. AGN, AF, CL, Leg. 267, marzo de 1853.

59. AGN, AF, CL, Leg. 267, marzo de 1853.

60. Decía Olivencia el 25 de abril: "siendo esta la tercera nota mía pues las dos anteriores han sido interceptadas y abiertas por los ranqueles”. Federico Olivencia al Cnel. Hilario Lagos AGN, Archivo Urquiza, abril de 1853.

61. Federico Olivencia al Cnel. Hilario Lagos. AGN, Archivo Urquiza, abril de 1853.

\section{ABSTRACTS}

From early December 1852 until mid-July 1853, Buenos Aires was immersed in an internal war resulting from a rebellion presided over by the federal military officers and seconded by the militias and neighbours from a great part of the countryside. The conflict broke out after the socalled "September 11th Revolution" that originally demanded the resignation of Valentín Alsina and the end of the war. During the duration of the conflict, the forces of the Federal Army and the National Guard of the city were mobilized and organized for a war that took place in several fronts: the city, the towns and the border. The indigenous factions were also part of the battle on both sides. In this paper we propose to analyze indigenous strategies in the context of the war that swept Buenos Aires. Above all, to study the areas affected by the "malones": the economic costs, the organization of the incursions as well as the consequences they provoked. We conclude that the different groups had their own strategies-both negotiation and open confrontationthat they took advantage of in their favour in a context of institutional fragility and sociopolitical change. The economic costs of the incursions were extremely important for the south of the province of Buenos Aires, especially the loss of livestock. The sources are varied and come mainly from the correspondence generated during the siege and organized in different repositories of the Archivo General de la Nación (AGN) and Archivo Histórico de la Provincia de Buenos Aires (AHPBA): Farini Archive, State of Buenos Aires, Urquiza Archive, Body 13 of Escribanía Mayor de Gobierno (EMG), Peace Court and Lagos File. 
Desde principios de diciembre de 1852 y hasta mediados de julio de 1853, Buenos Aires estuvo inmersa en una guerra intestina producto de una rebelión presidida por parte de la oficialidad militar federal y secundada por las milicias y vecinos de gran parte de los pueblos de campaña. El conflicto se desató luego de la llamada "Revolución del 11 de Septiembre" y pedía originalmente la renuncia de Valentín Alsina y el cese de la guerra. Durante la duración del conflicto, las fuerzas del Ejército Federal y la Guardia Nacional (GN) de la ciudad fueron movilizadas y organizadas para una guerra que se desarrolló en varios frentes: la ciudad, los pueblos y la frontera. Las parcialidades indígenas fueron también partícipes de la contienda en ambos bandos. En este artículo nos proponemos analizar desde la perspectiva criolla el accionar indígena en el contexto de la guerra que arrasaba a Buenos Aires. Sobre todo, estudiar las zonas damnificadas por los malones: los costos económicos, la organización de las incursiones como así también las consecuencias que provocaron. Concluimos que los diferentes grupos tuvieron estrategias propias - tanto de negociación como de enfrentamiento abierto- que supieron aprovechar en su favor en un contexto de fragilidad institucional y cambio sociopolítico. Los costos económicos de las incursiones fueron sumamente importantes para el sur de la provincia de Buenos Aires, sobre todo la pérdida de ganado. Las fuentes son variadas y provienen fundamentalmente de la correspondencia generada durante el sitio y organizada en diferentes repositorios del Archivo General de la Nación (AGN) y Archivo Histórico de la Provincia de Buenos Aires (AHPBA): Archivo Farini, Estado de Buenos Aires, Archivo Urquiza, Cuerpo 13 de Escribanía Mayor de Gobierno (EMG), Juzgado de Paz y Fondo Lagos.

\section{INDEX}

Palabras claves: Buenos Aires, indígenas, frontera, rebeliones federales, malones, siglo XIX Keywords: Buenos Aires, indigenous, frontier, federal rebellions, "malones”, 19th century

\section{AUTHOR}

\section{MARÍA FERNANDA BARCOS}

Instituto de Investigaciones en Humanidades y Ciencias Sociales, Universidad Nacional de La Plata

Consejo de Investigaciones Científicas y Técnicas, Argentina

Correo electrónico: mfbarcos@hotmail.com 